OLAVE, Alejandra "El delito de hurto como tipo de delito de resultado".

Polít. crim. Vol. 13, № 25 (Julio 2018) Art. 5, pp. 175-207.

[http://www.politicacriminal.cl/Vol_13/n_25/Vol13N25A5.pdf]

\title{
El delito de hurto como tipo de delito de resultado*
}

\section{Larceny as a result crime}

\author{
Alejandra Olave Albertini \\ Universidad de Chile \\ aolave@derecho.uchile.cl
}

\section{Resumen}

El artículo 494 bis del Código Penal ha resultado particularmente problemático al establecer una hipótesis de hurto en grado de frustrado, hipótesis que ha sido tildada como imposible por parte de la doctrina en Chile, por considerar al hurto un delito de actividad, categoría de delitos que sólo podrían darse en grado de tentativa (en los términos del artículo 7 del Código Penal). Esto ha llevado a algunos a la conclusión de que el art. 494 bis constituiría un error legislativo, toda vez que regularía una imposibilidad. El presente trabajo realiza una revisión de las categorías de actividad y de acción y el lugar que le corresponde al delito de hurto dentro de dicha clasificación. Dicha revisión llevará a clasificar al hurto como un tipo de acción, a saber, una constitutivamente compleja, en contraposición a aquellas acciones causalmente complejas. Al tratarse de una acción, el hurto sería un delito de resultado, lo que permite otorgarle sentido a la regulación del hurto falta, toda vez que no se trataría de la tipificación de una situación imposible. Se finalizará con una breve revisión de jurisprudencia acerca de la aplicación del hurto falta en Chile./

\section{Palabras clave:}

Hurto, hurto falta, delitos de actividad, delitos de resultado, hurto frustrado.

\begin{abstract}
Chilean legal doctrine often argues that larceny corresponds to an activity and not an action, which in turn makes it impossible for the offender to put everything on his part to achieve consummation, and not achieve it because of circumstances beyond his control, which could only happen in the case of actions according to them. The aim of this paper is to make sense of article 494 bis of the Chilean Penal Code, which regulates a specific case of attempted larceny in which the offender puts everything on his part to achieve consummation but doesn't, case rendered impossible by some scholars. To carry this out, it explores the difference between actions and activities and the place that corresponds to larceny in that classification, which will lead to classify larceny as a type of action, particularly a constitutive complex action, as different to those causal complex actions. This conclusion will allow us to make sense of Chilean regulation of larceny, as it is not impossible for the

\footnotetext{
${ }^{*}$ El presente trabajo ha sido desarrollado en el marco del Proyecto Fondecyt $\mathrm{N}^{\circ} 1160147$ (regular), en el cual la autora participa como tesista de magíster. La investigación consiste en una versión modificada de la segunda parte de mi memoria de licenciatura titulada "Hurto frustrado. Una propuesta de interpretación del artículo 494 bis del Código Penal", dirigida por el profesor Juan Pablo Mañalich, a quien agradezco especialmente por sus observaciones y sugerencias.
} 
Polít. crim. Vol. 13, № 25 (Julio 2018) Art. 5, pp. 175-207.

[http://www.politicacriminal.cl/Vol_13/n_25/Vol13N25A5.pdf]

regulated situation to happen. I will finish with a brief review of Chilean jurisprudence on the subject.

\section{Key words:}

Larceny, activities, actions, attempt of larceny.

\section{Introducción}

En el estudio de los delitos contra la propiedad, particularmente su regulación en Chile, una dificultad con la que actualmente se ha encontrado tanto la doctrina como la jurisprudencia es la tipificación del llamado "hurto falta", en el art. 494 bis del Código Penal que establece, en su inciso segundo, una pena específica en caso de que la falta se encuentre "en grado de frustrada". ${ }^{1}$ La dificultad radicaría en la imposibilidad del hurto de encontrarse en grado de frustrado, ${ }^{2}$ imposibilidad dada por la estructura propia del delito como un tipo de delito de aquellos llamados "de mera actividad", estructura que sólo permitiría que dichos delitos se encuentren en grado de tentativa (en el sentido de inciso tercero del art. 7 del Código Penal) o consumados.

El presente artículo pretende demostrar que la estructura típica del delito del hurto es una que se corresponde con los tipos de delito de resultado y no de actividad. Así, tratándose de un tipo de delito de resultado, es posible reconocer instancias de realización del tipo de hurto en las que el autor pone todo de su parte para que el delito se consume, sin que esto se verifique por causas independientes a su voluntad, lo que se corresponde con un hurto frustrado. El argumento a favor de la existencia del hurto frustrado permitirá defender la no irrelevancia de lo tipificado en el art. 494 bis.

Se comenzará con un análisis del tipo del hurto y sus elementos, examinando especialmente dos conceptos: el de custodia, cuya importancia radica en que su delimitación permitirá fijar el momento de consumación del hurto, y el de apropiación, el que tendrá especial importancia en la siguiente sección, para la clasificación del hurto dentro del binomio de tipos de delitos de actividad y de resultado. La segunda sección responde la pregunta acerca de si el hurto puede clasificarse como un delito de actividad, o si cae dentro del grupo de delitos cuyo tipo

\footnotetext{
${ }^{1}$ Un análisis crítico de la legislación que tipificaba el hurto falta al año 2005 se puede encontrar en FERNÁNDEZ, Álvaro, "Hurto-falta: Una reforma mal hecha y otra pendiente", Sentencias destacadas, Anuario de jurisprudencia: una mirada desde la perspectiva de las políticas públicas, Libertad y Desarrollo, (2005), pp. 89-104.

${ }_{2}^{2}$ En el presente trabajo la distinción establecida en el artículo 7 del Código Penal, entre tentativa y delito frustrado, se considerará equivalente a la distinción, originalmente alemana, entre tentativa acabada e inacabada, de acuerdo a la posición mayoritaria de la doctrina nacional. Por ello, deberá entenderse en adelante que tentativa inacabada equivale a tentativa, y que tentativa acabada equivale a delito frustrado, en los términos del artículo 7 del Código Penal. CURY, Enrique, Derecho Penal parte general, $7^{a}$ ed., Santiago: Ediciones Universidad Católica de Chile, 2005, p. 564, GARRIDO, Mario, Derecho Penal, Parte General, Tomo II, $3^{a}$ ed. Santiago: Editorial Jurídica, 2003, p. 281 y p. 283, NOVOA, Curso de derecho penal chileno, Tomo II, 3 a ed. Santiago, Editorial Jurídica, 2005, p. 125. Si bien, la estricta equiparación entre los términos utilizados en el artículo 7 y los conceptos de tentativa acabada e inacabada no es unánime en la doctrina (en contra, POLITOFF, Sergio, Los actos preparatorios del delito: tentativa y frustración, Santiago: Editorial Jurídica de Chile, 1999, p. 214, con ulteriores referencias), los argumentos que se presentan en este trabajo se mantienen en todo caso si se utiliza únicamente la definición de delito frustrado y tentativa del art. 7, sin equipararlos a los conceptos de tentativa acabada e inacabada.
} 
OLAVE, Alejandra "El delito de hurto como tipo de delito de resultado".

requiere un determinado resultado, profundizando en dicha clasificación. Una vez aplicada la distinción entre tipos de delitos de actividad y tipos de delitos de resultado al hurto, se procederá a analizar cómo se puede dar en calidad de frustrado.

Se finalizará con la aplicación de lo concluido a los casos del llamado "robo hormiga" en establecimientos de autoservicio, casos en los que suele discutirse la aplicación del art. 494 bis. Éstos se caracterizan, primero, por su alta frecuencia en Chile, correspondiendo el hurto a un $11 \%$ de las causas ingresadas al sistema del Ministerio Público, siendo el segundo delito más frecuente junto con las lesiones y los delitos contra la libertad e intimidad de las personas. ${ }^{3}$ En segundo lugar, los delitos de hurto en establecimientos de autoservicio se caracterizan por la dificultad que presentan al momento de establecer sus etapas de realización, en particular porque se trata de casos en que los objetos sustraídos se encuentran presentados en vitrinas, con la finalidad de facilitar el autoservicio de los clientes.

\section{El tipo del hurto}

\subsection{Concepto de apropiación}

El artículo 432 requiere una apropiación de cosa mueble ajena sin la voluntad de su dueño y con ánimo de lucrarse. Lo primero que debe decirse sobre el concepto de apropiación es que éste, a pesar de no ser completamente independiente a la regulación de la propiedad en materia civil, no puede depender de lo que civilmente se entiende por apropiación (título traslaticio de dominio, unido a un modo de adquirirlo). Mientras la posición del dueño es una reconocida y protegida por el ordenamiento jurídico, quien se apropia de un bien mueble ajeno, cometiendo un delito contra la propiedad, no se encuentra en semejante posición (de ahí que la posibilidad del dueño de reivindicar los objetos que le pertenecen permanezca intacta). ${ }^{4}$ La razón por la que el concepto de apropiación debe entenderse de forma absolutamente independizada de lo que se establece a su respecto en la regulación civil es que el autor ha de comportarse tal como si tuviese un derecho de propiedad sobre la cosa. La pretensión de exclusividad sobre la cosa, propia del derecho de dominio, es lo que se reconoce en quien se apropia, en términos del art. 432. Como lo define Kindhäuser, “(...) apropiación es un acto a través del cual el autor toma en posesión en nombre propio una cosa ajena con la pretensión de disponer exclusivamente sobre ella excluyendo a otros". 5

\footnotetext{
${ }^{3}$ Boletín anual enero-diciembre 2016, Ministerio Público [en línea]:

<http://www.dpp.cl/resources/upload/files/documento/3a11ed0c600a87c84d4b07eaffc937c3.pdf> [consultada 14/06/2017].

${ }^{4}$ ETCHEBERRY, Alfredo, Derecho Penal, Parte Especial, Tomo III, $3^{a}$ ed. Santiago: Editorial Jurídica, 1997, p. 296, y VERA, Juan Sebastián, La consumación en el hurto, Santiago: Librotecnia, 2011, p. 126.

${ }^{5}$ KINDHÄUSER, Urs, Estudios de Derecho Penal Patrimonial, Lima: Grijley, 2002, p. 55. Si bien la doctrina en Chile reconoce la independencia de ambos conceptos en el sentido de que el concepto civil de apropiación no ha de limitar la forma en que se entiende penalmente dicho concepto, en todo caso utiliza reconstrucciones dogmático-civiles para comprender los alcances de la apropiación y el ánimo de apropiación. Así, por ejemplo, Garrido se refiere al concepto utilizando como aquél en el que "(...) el delincuente se arroga las facultades de uso, goce y disposición (...)" (GARRIDO, Derecho Penal, Parte Especial, Tomo IV, 4a ed. Santiago: Editorial Jurídica, 2008, p. 159); Politoff, Matus y Ramírez se refieren a la apropiación como una que "(...) consiste en la sustracción de la cosa con ánimo de señor y dueño (animus rem sibi habendi)" (POLITOFF, Sergio; MATUS, Jean Pierre y RAMÍREZ, Cecilia, Lecciones de Derecho Penal chileno, Parte General, $2^{a}$ ed. Santiago: Editorial Jurídica, 2004, p. 206). En ese sentido, no se intenta negar que exista independencia del concepto de apropiación penal de aquél que se utiliza en el ámbito del Derecho Civil, sino sólo enfatizar que la construcción
} 
Polít. crim. Vol. 13, № 25 (Julio 2018) Art. 5, pp. 175-207.

[http://www.politicacriminal.cl/Vol_13/n_25/Vol13N25A5.pdf]

Como dicha toma de posesión en nombre propio de algo ajeno no está reconocida por el derecho, su identificación trae aparejada diversos problemas de índole probatorio que exceden los límites del presente trabajo. La dificultad principal radica en la identificación de la pretensión de exclusividad que deberá presentar el autor. ${ }^{6}$ Lo importante es comprender que, mientras persista el reconocimiento de propiedad ajena (ya sea porque el autor pretende devolver la cosa, como en el hurto de uso, o porque nunca quiso apropiársela, sino sólo destruirla, como en el daño), no se podrá reconocer apropiación y, por ello, no habrá hurto.

En cuanto a la caracterización del objeto de apropiación como mueble, la mayor parte de la doctrina, tanto nacional como extranjera, concuerda en que debe tratarse de una cosa corporal. ${ }^{7}$ En cuanto a su caracterización como objeto mueble, a pesar de que antiguamente se privilegiaba una "concepción privatista", referida a que por "objeto mueble" debía entenderse el concepto civil, actualmente la gran mayoría de la doctrina asume una "concepción autonomista", no siendo aplicable la definición civil al concepto de cosa mueble utilizado por el Código Penal. ${ }^{8}$

La caracterización de la cosa como ajena permite descartar hurto en caso de que el objeto pertenezca a quien lo sustrae (en caso de error, por ejemplo), como también en caso de que se trate de cosas que no pertenezcan a nadie, tal como ocurre con las res nullius o res derelictae. ${ }^{9}$ El requisito de ajenidad da luz acerca del sentido de la acción del autor en el hurto: debe tratarse de un desconocimiento del dominio del titular sobre la cosa, desconocimiento que está dado por la expropiación de ésta. Para efectuar dicha expropiación, será necesario que el autor quebrante la custodia ajena establecida sobre la cosa: éste siempre deberá "sacar" al objeto de la custodia ajena. ${ }^{10}$ A pesar de que el art. 432 no se refiere a una

dogmática que se haga sobre el concepto de apropiación no deberá ignorar aquella que se ha hecho en el Derecho Civil, particularmente respecto al ánimo de apropiación.

${ }^{6}$ Tal como lo plantea KINDHÄUSER, Estudios, cit. nota ${ }^{\circ} 5$, pp. 55 y ss., para la percepción externa de la apropiación hay que reconocer indicios que permitirán identificar la pretensión de exclusividad y falta de reconocimiento del dominio del titular, por parte del autor.

${ }^{7}$ Por todos, véase OLIVER, Guillermo, Delitos contra la Propiedad, Santiago: Thompson Reuters, 2013, pp. 94 y ss., con ulteriores referencias.

${ }^{8}$ VERA, Juan Sebastián, La consumación, cit. nota n 4, pp. 138 y ss., OLIVER, Delitos contra la Propiedad, cit. nota $\mathrm{n}^{\circ} 7$, pp. 97 y ss., con ulteriores referencias.

${ }^{9}$ Sobre este requisito y las diversas discusiones que ha suscitado (en particular, si puede afirmarse que hay hurto en el caso de que sea un copropietario que se apropie de la cosa común), véase OLIVER, Delitos contra la Propiedad, cit. nota $\mathrm{n}^{\circ} 7$, pp. 100 y ss.

${ }^{10}$ Con respecto a la sustracción como parte necesaria de la apropiación en el hurto, Yáñez propone “(...) entender la apropiación como un simple hacer suyo, independiente de la forma en que se haga, distinguiéndolo del sustraer, que implica acción positiva de sacar lo que antes no era suyo, concepción incompatible con la figura de apropiación indebida." YÁÑEZ, Rodrigo, "Una revisión crítica de los habituales conceptos sobre el íter criminis en los delitos de robo y hurto", Política Criminal Vol. 4, n 7, (2009), p. 92. Énfasis en el original. Efectivamente, el art. $470 \mathrm{~N}^{\circ} 1$ también utiliza el concepto de apropiación, llevando a Yáñez a la conclusión de que en el hurto el concepto de apropiación deberá ser entendido de forma distinta, sin incluir la sustracción. Sin embargo no es necesario llegar a esa conclusión (en el mismo sentido, OLIVER, Delitos contra la Propiedad, cit. nota $\mathrm{n}^{\circ} 7$, pp. 70-1). Entendiendo apropiación como la pretensión de dominio sobre la cosa, en ambos tipos el concepto es el mismo. La diferencia está en la forma en que se manifiesta la pretensión: dado que en la apropiación indebida la cosa ya se encuentra bajo la custodia del autor, la sustracción no es necesaria. Así, la apropiación en el caso del art. $470 \mathrm{~N}^{\circ} 1$ consiste en "una acción que importe un absoluto desconocimiento de cumplir con su obligación [la del autor] de 'entregar' o 'devolver' la 'cosa' (...)”. SOTO, Miguel, La apropiación indebida, Santiago: Conosur, 1994, p. 50. En el hurto, en cambio, la única forma de apropiarse de la cosa es venciendo la custodia ajena, lo que se realiza a través de la sustracción. Sobre el problema de entender 
OLAVE, Alejandra "El delito de hurto como tipo de delito de resultado".

apropiación mediante sustracción, parte de la doctrina nacional ${ }^{11}$ ha reconocido la sustracción como un elemento necesario del hurto, toda vez que el Código Penal reconoce casos de apropiación sin sustracción, como el hurto de hallazgo, tipificado en el art. $448 .{ }^{12}$

Una vez quebrantada la custodia, el autor constituye a su vez una nueva custodia. Esta dualidad expropiación / apropiación en el hurto abre la posibilidad de que, por contraste, existan las variantes de expropiación sin apropiación y de apropiación sin expropiación. El primer caso consiste en el llamado "hurto de uso", el cual no se encuentra tipificado en nuestro Código Penal y consiste en la sustracción con la finalidad de utilizar el objeto, para luego devolverlo a su dueño, el cual en todo momento sigue siendo reconocido por el autor como tal. El segundo caso se corresponde, como se dijo, con el hurto de hallazgo y, en algunos casos, ${ }^{13}$ con la apropiación indebida.

Ahora bien, el reconocimiento de la extensión y límites de la custodia no es en caso alguno evidente.

"El concepto de 'esfera de custodia' es abstracto, y su significación concreta variará en cada caso; de este modo, es posible que en ciertas circunstancias el poder de hecho sobre la cosa pueda adquirirse con la simple remoción (amotio) de la misma, pero ello no ocurrirá siempre y necesariamente." 14

La aproximación clásica en Chile al concepto de custodia ${ }^{15}$ utiliza la metáfora espacial de "esferas de custodia", refiriéndose a lo que se puede entender como cierto espacio en el que un sujeto ejerce su custodia sobre diversos bienes, resguardándolos. Así, podría reconocerse que el bolso de un hombre es la esfera de custodia de las cosas que están dentro; su casa, una esfera mayor que contiene otros bienes y al bolso, y así sucesivamente. El problema de la metáfora espacial es que pierde de vista que la custodia no se corresponde con un espacio que pueda delimitarse como un campo de fuerza que rodea al sujeto y al o los bienes en cuestión. ${ }^{16}$ Más bien, la custodia es una relación fáctica entre un sujeto y un objeto, relación que emana de la facultad del dueño de excluir a otros del uso, goce y disposición de la cosa. Dicha relación de custodia puede manifestarse de diversas formas que serán reconocibles gracias a indicios, tales como la cercanía espacial entre el sujeto y el objeto que tiene bajo su custodia; la utilización de espacios físicos para resguardar objetos, como mochilas o bolsas; la presencia de elementos de seguridad, como candados o cadenas. Estos indicios permitirán

la apropiación indebida como delito contra la propiedad en caso de obligaciones de dinero y una propuesta interpretativa del art. $470 \mathrm{~N}^{\circ}$ 1, HERNÁNDEZ, Héctor "La administración desleal en el derecho penal chileno", Revisa de Derecho de la Pontificia Universidad Católica de Valparaíso XXVI, (2005), p. 210 y ss.

${ }^{11}$ Por todos, OLIVER, Delitos contra la Propiedad, cit. nota ${ }^{\circ} 7$, pp. 68 y ss.

${ }^{12}$ La postura que afirma que la sustracción es un elemento necesario para la realización del tipo del hurto ha sido criticada por Vera, quien afirma que “(...) la sustracción constituye solo uno de los modos o formas por los cuales se puede realizar la apropiación, pues todos los medios son aptos para consumar el hurto, excepto la violencia.” VERA, Juan Sebastián, La consumación, cit. nota $n^{\circ}$ 4, p. 235. Así, propone que la conducta típica en el hurto sea entendida en dos fases, una de desapropiación o expropiación y otra de apropiación propiamente tal (p. 243). Sobre este punto se volverá más abajo.

${ }^{13}$ Véase supra, nota 10.

${ }^{14}$ ETCHEBERRY, Derecho Penal, Parte Especial, cit. nota ${ }^{\circ} 4$, p. 297. Igualmente, reconociendo además que éste “(...) bajo ningún punto constituye un puro concepto geográfico susceptible de ser medido a través de distancias rígidas", VERA, Juan Sebastián, La consumación, cit. nota n 4, p. 200.

${ }^{15}$ Por todos, YÁÑEZ, "Una revisión crítica”, cit. nota n 10, p. 30.

${ }^{16}$ En el mismo sentido, VERA, Juan Sebastián, La consumación, cit. nota n 4, p. 200. 
Polít. crim. Vol. 13, № 25 (Julio 2018) Art. 5, pp. 175-207.

[http://www.politicacriminal.cl/Vol_13/n_25/Vol13N25A5.pdf]

reconocer su existencia. Su extensión, por otro lado, estará dada por el -crucialreconocimiento del momento en que se quebranta por completo, es decir, del momento de la consumación del delito de hurto. ${ }^{17}$ Por lo anterior, no basta simplemente con un criterio espacial del reconocimiento de custodia, tal como ha sido reconocido por las modernas teorías acerca del alcance de lo que debe entenderse por "custodia", que no se basan exclusivamente en indicios "físicos" u "espaciales" sino también culturales y normativos. ${ }^{18}$

Ahora bien, criticando la caracterización del delito de hurto como uno en el que existe ruptura de custodia ajena, Vera afirma que "[d] esde el punto de vista del estatuto del dominio, esta teoría, indefectiblemente, conduce a inferir que quien no ejerce una custodia sobre la cosa, no es dueño de ella." ${ }^{19}$ Ello, porque existen casos en los que el dueño puede decidir no ejercer custodia alguna sobre la cosa, como "(...) el viajero que abandona momentáneamente sus maletas en el aeropuerto para ir a los servicios higiénicos (...)" ${ }^{20}$ En efecto, el dueño puede decidir no ejercer custodia alguna sobre uno o varios bienes. Dichos bienes, en caso de inexistencia de custodia, deberán ser reconocidos como especies al parecer perdidas, sobre las que no existirá sustracción previa a la apropiación (precisamente porque no existe custodia). En estos casos se estará ante un hurto de hallazgo, tipificado en el art. 448 del Código Penal. ${ }^{21}$

La exigencia de ruptura de custodia para la configuración del delito de hurto no implica en caso alguno " (...) adicionar un requisito constitutivo al estatuto dominical (...)". ${ }^{22}$ Y en nada cambia esto el hecho de que quien decide no ejercer custodia sobre sus bienes, sepa en qué lugar se encuentran. Ello, porque el la regulación de la especies al parecer perdidas no "(...) atiende al estatuto del propietario de la cosa (si tiene o no dueño), sino a lo que es visible para el hallador, para quien se enfrenta a la cosa." ${ }^{23}$ Lo relevante entonces, está en cómo se

${ }^{17}$ Como se verá, la mayoría de la doctrina considera que el momento de la consumación del hurto es el de la destrucción de la custodia y creación de una nueva custodia ajena. La excepción a esta postura se encuentra en la teoría de la disponibilidad, la que reconoce que puede haber quebrantamiento de custodia sin consumación, por no existir todavía para el autor posibilidad de disponer del bien. Por esto, afirmar que el momento de la consumación está dado por el momento en que la custodia se quebrante por completo implica negar la teoría de la disponibilidad. Véase, infra pp. 7 y ss.

${ }_{18}$ Así, por ejemplo, BASCUÑÁN, Antonio, "Delitos contra intereses instrumentales", Revista de Derecho de la Universidad Adolfo Ibáñez I (2004), pp. 300 y ss., VERA, Juan Sebastián, La consumación, cit. nota $\mathrm{n}^{\circ} 4$, pp. 231 y ss.

${ }^{19}$ VERA, Juan Sebastián, La consumación, cit. nota ${ }^{\circ}$ 4, p. 207.

${ }^{20}$ VERA, Juan Sebastián, La consumación, cit. nota ${ }^{\circ}$ 4, p. 203.

${ }^{21}$ Ya que el reconocimiento de custodia depende de ciertos indicios, existirán casos en los que resulte difícil determinar si es que se sigue ejerciendo custodia o si ésta ya no existe. Ahora bien, la determinación precisa de los límites entre especies custodiadas y al parecer perdidas excede los límites del presente trabajo.

${ }^{22}$ Así, Oliver afirma que “[e]n efecto, el artículo 448 CP. contempla el denominado 'hurto de hallazgo', que consiste, en términos generales, en encontrarse especies muebles al parecer perdidas o abandonadas y no entregarlas a su dueño o a la autoridad. En estos casos, la cosa objeto del delito se encuentra fuera de la custodia de su titular. Por lo tanto, resulta forzoso entender que para que tenga lugar la apropiación en un hurto o en un robo, es necesario que la cosa aún se encuentre bajo la esfera de custodia o resguardo de su titular, esfera desde la cual debe ser sustraída." OLIVER, Guillermo, "Estructura típica común de los delitos de hurto y robo", Revista de derecho de la Pontificia Universidad Católica de Valparaíso XXXVI, (2011), p. 361. Asimismo, OLIVER, Delitos contra la Propiedad, cit. nota n ${ }^{\circ} 7$, pp. 174 y ss.

${ }^{23}$ ATRIA, Fernando, "Sobre el título en la posesión, las cosas al parecer perdidas y la ocupación”, en: SCHOP, Adrián; MARÍN, Juan Carlos (Eds.), Lo público y lo privado en el derecho, estudios en homenaje al profesor Enrique Barros Bourie, Santiago: Legal Publishing Chile, 2017, p. 869. Sin embargo, VERA, Juan Sebastián, La consumación, cit. nota $\mathrm{n}^{\circ} 4$, nota 613 , quien afirma que “(...) el dueño de una cosa 'al parecer perdida' 
OLAVE, Alejandra "El delito de hurto como tipo de delito de resultado".

presenten dichos bienes para quien se encuentra con ellos. Nuevamente se vuelve acá a la idea de indicios que permitirán inferir si es que se trata de una cosa sobre la que todavía existe una relación de custodia que hace ilícita su sustracción con ánimo de apropiación. Así, en el caso de una empresa constructora que deposita arena al costado de la vía pública para una de sus construcciones, el que se trate de un montículo de arena y no arena esparcida por la calle y que esté junto a una construcción son dos hechos que hablan a favor de que no se trata de una especie al parecer perdida, sino que la empresa constructora ejerce custodia sobre dicha arena (confiando, por ejemplo, en lo difícil que sería llevársela sin las herramientas apropiadas). ${ }^{24}$

\subsection{La apropiación como elemento normativo del tipo}

Un punto importante sobre el concepto de apropiación está relacionado con los alcances del dolo y la distinción entre elementos descriptivos y normativos del tipo, relacionándose el concepto de apropiación con esta última categoría. Los elementos descriptivos del tipo han sido usualmente definidos como aquéllos que son “(...) susceptibles de ser captados por los sentidos, es suficiente tener conocimiento de su identidad, no requieren de un razonamiento o valoración para aprehenderlos". ${ }^{25}$ Los elementos normativos, por su parte, serían aquéllos que no pueden captarse simplemente por los sentidos, sino que requieren una valoración específica de quien los conoce. Bajo esta caracterización, la apropiación sería un elemento normativo, ya que se requeriría criterios adicionales a la sola percepción para determinar si una cosa está en propiedad, de tenencia o ninguna, respecto a determinada persona.

La importancia de esta distinción radicaría, bajo dicha caracterización, en sus consecuencias para el error. En el caso de que el error recayera sobre un elemento descriptivo del tipo, se estaría ante un error de tipo, ya que dependería de la representación de los hechos, de acuerdo a la percepción del autor. Por otro lado, si recayera sobre un elemento normativo del tipo, se estaría ante un error de prohibición, ya que consistiría en una equivocada valoración (jurídica) de los hechos.

La dificultad de esta comprensión se encuentra en que la distinción entre elementos descriptivos y normativos no es evidente. Por ejemplo, para reconocer que una persona es menor de 14 años, en el sentido del artículo 362, no basta con la percepción sensorial, aunque ésta resulta en cualquier caso útil. Se necesita también manejar el concepto de edad y cómo se calcula, lo que recaería en la categoría de valoraciones específicas no captables por los

\footnotetext{
desconocería la ubicación espacial de la cosa (...).” El conocimiento o desconocimiento del lugar en donde las cosas se encuentran es irrelevante para la realización del tipo. Lo relevante está en el que las cosas se encuentren bajo custodia (OLIVER, Delitos contra la Propiedad, cit. nota ${ }^{\circ}$ 7, p. 179). Respecto al mismo punto, sostiene que no siempre cosas no custodiadas aparecen ante la sociedad como perdidas. El punto es que si dichas cosas no "aparecen ante la sociedad" como perdidas, esto implica un reconocimiento (que puede ser muy débil) de custodia ajena. Si no es posible reconocer custodia alguna, entonces dichas especies en efecto serán reconocibles como "al parecer perdidas".

${ }^{24}$ El ejemplo propuesto por Vera (VERA, Juan Sebastián, La consumación, cit. nota n 4, p. 203) y sacado de GARRIDO, Derecho Penal, Parte Especial, cit. nota ${ }^{\circ}$ 5, p. 160, es utilizado por el primero como ejemplo de un bien sobre el que se tiene derecho de dominio pero no se ejerce custodia. Es una feliz coincidencia que Atria cite un ejemplo similar para distinguir entre cosas abandonadas y cosas al parecer perdidas. ATRIA, "Sobre el Título", cit. nota ${ }^{\circ} 23$, pp. 890-892.

${ }^{25}$ GARRIDO, Derecho Penal, cit. nota ${ }^{\circ} 2$, p. 53.
} 
sentidos. En este sentido, no es la distinción entre elementos descriptivos y normativos la que permite diferenciar entre error de tipo y error de prohibición.

El error en las circunstancias que hace creer aplicable un determinado elemento de la descripción típica que no es objetivamente aplicable (o viceversa) a dichas circunstancias es un error de tipo. En el caso del predicado "menor de 14 años", por ejemplo, ciertas características físicas de la persona hacen creer que nació hace menos de 14 años atrás. Por otra parte, quien yerra acerca de la edad de una persona por creer que ésta se calcula según el año de ingreso a la educación primaria y no según la fecha de nacimiento, no yerra en su representación de las circunstancias objetivamente dadas, sino que se equivoca en el sentido del elemento típico que está aplicando a tales circunstancias: no entiende lo que es un menor de 14 años (ya que no entiende correctamente el concepto de "edad"). En este caso, se trata de un error de prohibición. ${ }^{26}$

El error de tipo, por tanto, recae en las "circunstancias fácticas de las cuales depende (objetivamente) la antinormatividad del hecho", ${ }^{27}$ y consiste en la representación -erradade que determinadas circunstancias fácticas permiten la satisfacción de las condiciones de verdad de una proposición. Por su parte, el error de prohibición recae en el conocimiento de la antinormatividad del hecho. Lo que se ignora no es que en un caso particular se satisfacen las condiciones de verdad de una proposición, sino que se ignora el sentido de la proposición.

A la inversa, el error puede igualmente recaer sobre presupuestos fácticos o normativos que hacen creer que se está cometiendo un delito. En el caso del error en presupuestos fácticos, se trata de una tentativa; en el caso de error en presupuestos normativos, un delito putativo.

\section{3. Ánimo de lucro}

En el binomio de delitos contra el patrimonio y contra la propiedad, la exigencia establecida en el tipo de hurto, de que la apropiación se realice con ánimo de lucrarse, resulta anómala, ya que parece apuntar a que la apropiación se realice con la finalidad de lograr un beneficio patrimonial. Ello no es necesariamente así, ya que bajo un concepto funcional de patrimonio, el hurto puede recaer sobre objetos que carecen objetivamente de valor de mercado. ${ }^{28}$

En cuanto a su relación con el ánimo de apropiación, si se entiende que quien ejecuta la conducta típica correspondiente al delito de hurto se comporta respecto al bien sustraído tal como si tuviese un derecho de propiedad sobre éste, entonces puede entenderse que su comportamiento incluirá la expectativa (no protegida jurídicamente, en este caso) de goce de la cosa, es decir, de aprovechamiento de ésta. Así, el ánimo de lucro debe entenderse como

\footnotetext{
${ }^{26}$ KINDHÄUSER, "Acerca de la distinción entre error de hecho y error de derecho", en: VV.AA. El error en el Derecho Penal, Buenos Aires: AD-HOC, 2010, pp. 157-8.

${ }^{27}$ MAÑALICH, "El delito como injusto culpable", Revista de Derecho Vol. XXIV, n 1, (2011), p. 105.

${ }^{28}$ Véase KINDHÄUSER, Estudios, cit. nota n ${ }^{\circ} 5$, p. 32. Bajo este concepto, se toma el punto de vista del titular del bien para determinar el "valor" de éste, permitiendo así que cosas que carecen de valor de mercado sean en todo caso consideradas como parte del objeto de protección de las normas que establecen los delitos contra la propiedad (un bien de escaso valor en el mercado, que incluso le reporte pérdidas patrimoniales a su dueño, es igualmente objeto de protección de la norma que tipifica el delito de hurto). Ahora bien, el argumento del presente trabajo se sostiene incluso negando que el hurto pueda recaer sobre objetos que carecen objetivamente de valor de mercado, como lo hace la mayor parte de la doctrina en Chile. Por todos, véase OLIVER, Delitos contra la Propiedad, cit. nota ${ }^{\circ}$ 7, pp. 105 y ss., con ulteriores referencias.
} 
OLAVE, Alejandra "El delito de hurto como tipo de delito de resultado".

un componente de la apropiación, ${ }^{29}$ como tendencia interna trascendente de aprovechamiento. ${ }^{30}$ Esto último dista de ser una postura unánime. Hay, por una parte, quienes defienden que el ánimo de lucro está en una relación género-especie con el ánimo de apropiación, ${ }^{31}$ (siendo entonces innecesaria la referencia al ánimo de lucro en los delitos que utilizan la expresión “apropiación”) ${ }^{32}$ y por otra, quienes (como Garrido y Etcheberry) plantean que no debe entenderse al ánimo de lucro como parte de la exigencia subjetiva del ánimo de apropiación, sino como un aprovechamiento particular de cualquier tipo, que sea económicamente apreciable. ${ }^{33}$

Esta última comprensión del ánimo de lucro muestra una confusión entre delitos contra la propiedad y delitos contra el patrimonio, derivada principalmente del hecho de que la pena en el hurto se gradúa conforme al valor pecuniario de la cosa sustraída. ${ }^{34}$ Etcheberry, en particular, defiende su postura utilizando como ejemplo el caso de quien sustrae para destruir posteriormente, recibiendo un provecho sicológico del hecho de destruir algo ajeno, defendiendo que en este caso no habría hurto por falta de ánimo de lucro, toda vez que ese provecho no es económicamente apreciable. El problema de este ejemplo está en que no resulta clara la distinción que se pretende mostrar, entre ánimo de lucro y ánimo de apropiación. Ello, porque en el caso que se propone, precisamente el autor no se ve a sí mismo como dueño, sino que continúa reconociendo dominio ajeno (de ahí el placer que recibe al destruir el objeto). Mientras persista este reconocimiento, no existirá apropiación (y, por lo tanto, tampoco habrá aprovechamiento). Así, se descarta la aplicación del hurto no por falta

${ }^{29}$ ZUGALDÍA, "Delitos contra la propiedad y el patrimonio", Revista Chilena de Derecho, Vol.15, n², 1988, pp. 42 y ss. Es importante señalar que en este caso se está considerando que el ánimo de lucro es un componente de la apropiación, no un tipo específico de ánimo de apropiación. Por lo mismo, el ánimo de lucro puede presentarse de forma independiente, como sería en el caso del hurto de uso. Asimismo, POLITOFF / MATUS / RAMÍREZ, Lecciones, cit. nota n ${ }^{\circ}$ 5, p. 306. Es importante señalar que Matus y Ramírez cambian su postura en la edición 2017 de las Lecciones, afirmando que la posición antes defendida llevaría a eliminar la diferencia entre el delito de hurto y daños "(...) pues en los segundos el ejercicio del poder material de disposición (destrucción) de quien aprehende algo ajeno, no parece distinguirse el poder de disposición jurídicamente reconocido al dueño legítimo." MATUS, Jean Pierre y RAMÍREZ, Cecilia, Manual de derecho penal chileno: parte especial, Valencia: Tirant Lo Blanch, 2017, p. 345. Al respecto, infra, nota $\mathrm{n}^{\circ} 35$.

${ }^{30}$ MAÑALICH, Juan Pablo, "La tentativa y el desistimiento en el derecho penal. Algunas consideraciones conceptuales", Revista de Estudios de la Justicia n ${ }^{\circ}$ 4, (2004), p. 162. Así, el hurto consiste en un delito que, además del dolo referido a la apropiación, requiere de un elemento subjetivo adicional como lo es el ánimo de aprovechamiento de la cosa. Dicho aprovechamiento de la cosa no es requerido para la consumación, sino que se corresponde con la etapa de agotamiento del delito.

${ }^{31}$ MAYER, Laura, "El ánimo de lucro en los delitos contra intereses patrimoniales", Revista de Derecho de la Pontificia Universidad Católica de Valparaíso XLII, (2014), pp. 301-303.

32 OLIVER, Delitos contra la Propiedad, cit. nota $\mathrm{n}^{\circ} 7$, p. 86. Asimismo, aceptando que bajo ella se torna superfluo el requisito de ánimo de lucro como mal menor en comparación con adoptar una postura distinta, MAYER, "El ánimo de lucro", cit. nota n 31, p. 303.

${ }^{33}$ GARRIDO, Derecho Penal, Parte Especial, cit. nota n ${ }^{\circ}$ 5, nota 40 y pp. 170-1; ETCHEBERRY, Derecho Penal, Parte Especial, cit. nota n ${ }^{\circ}$ 4, pp. 305 y ss.; OLIVER, Delitos contra la Propiedad, cit. nota n ${ }^{\circ}$ 7, pp. 85 y ss.

${ }^{34}$ Aunque no es necesario llegar a dicha conclusión, toda vez que podría defenderse que la variante de hurto falta no establece un monto mínimo de valor para la cosa, sino que sólo establece un monto máximo para tratarse de la falta. Ahora bien, ello dependería de la posibilidad de argumentar, desde un concepto funcional de patrimonio, que al referirse a "valor", el artículo no se refiere exclusivamente a "valor económico". Así, ZUGALDÍA, "Delitos contra la propiedad", cit. nota n ${ }^{\circ} 29$, p. 27. La mayoría de la doctrina en Chile, sin embargo, se manifiesta en contra de esta interpretación. Por todos, OLIVER, Delitos contra la Propiedad, cit. nota $\mathrm{n}^{\circ}$, pp. 105 y ss., con ulteriores referencias. 
Polit. crim. Vol. 13, № 25 (Julio 2018) Art. 5, pp. 175-207.

[http://www.politicacriminal.cl/Vol_13/n_25/Vol13N25A5.pdf]

de ánimo de lucro sino precisamente por falta de apropiación. El ejemplo planteado es un claro caso de delito de daños, que corresponde a un delito de expropiación sin apropiación correlativa.

Por lo anterior, el ánimo de lucro será considerado como parte del ánimo de apropiación que debe estar presente en la realización del tipo por parte del autor, como tendencia interna trascendente. Ésta será el elemento subjetivo adicional, reconocible en la realización del tipo, de hacerse de la cosa como señor y dueño. ${ }^{35}$

\subsection{Momento de la consumación}

Las teorías tradicionales ${ }^{36}$ sobre el momento de consumación del hurto se pueden dividir según el instante en el que lo fijan. De entre estas, las más tratadas por la doctrina nacional ${ }^{37}$ son la de la contractatio, que establece que basta el contacto físico del autor con la cosa (tocarla) para que el delito esté consumado; la de la aprehensio rei, que se establecería un requisito adicional a la de la contractatio, exigiendo no sólo el tocar el bien, sino la aprehensión de éste; la teoría de la amotio, que exige que el objeto sea removido del lugar donde está y trasladado a otro distinto; la de la ablatio, que requiere que la cosa sea sacada del lugar físico en el que se encuentra; y la de la illatio que establece la consumación al momento en que la cosa arriba al lugar que el autor se proponía. ${ }^{38}$ A éstas se suma la teoría de la disposición, propuesta por Mario Garrido, ${ }^{39}$ quien afirma que se da la consumación “(...) cuando el delincuente se encuentra en la posibilidad de ejercer esa facultad [de disposición], cuando logra estar en condiciones de disponer de la cosa ajena (...), siquiera por un instante". ${ }^{40}$

Esta teoría, como ha sido reconocido por la doctrina, ${ }^{41}$ tiene el problema de establecer la consumación en un momento excesivamente tardío, confundiendo consumación con el agotamiento del delito. Como explica Bascuñán,

"semejante construcción erosiona la base de la distinción sistemática entre delitos de apropiación con ruptura de la custodia ajena y delitos de apropiación sin ruptura de la

\footnotetext{
${ }^{35}$ Esto lleva a que, en caso de que el autor sustraiga la cosa con la intención de apropiársela, pero luego se arrepienta y la destruya, se tendrá un concurso aparente entre hurto y daños, que se resuelve a favor del primero, dada la cláusula de subsidiariedad establecida en el art. 488.

${ }^{36}$ También llamadas teorías de origen histórico por VERA, Juan Sebastián, La consumación, cit. nota n 4, pp. 189 y ss.

${ }^{37}$ Por todos, POLITOFF / MATUS / RAMÍREZ, Lecciones, cit. nota n ${ }^{\circ}$ 5, p. 309.

${ }^{38}$ También puede mencionarse la teoría de la locupetatio, que considera consumado el delito cuando el autor cumple su finalidad, obteniendo el provecho deseado. Al respecto, se comparten las críticas que plantea Vera, sobre la confusión entre consumación y agotamiento, estableciendo un requisito para la consumación no previsto en el artículo 432. VERA, Juan Sebastián, La consumación, cit. nota nº 4, pp. 211-2.

${ }^{39}$ En Alemania esta teoría encuentra su símil en la tesis postulada por Kahlo, quien plantea las consecuencias específicas que tendría para el caso de hurto en establecimientos de autoservicio. La postura de Kahlo coincide con la defensa de la hoy mayoritaria jurisprudencia en Chile, de que la consumación se logra al momento de traspasar la línea de las cajas. KAHLO, "Determinación conceptual del derecho e interpretación sincrética en las relaciones de pertenencia propias del tipo de hurto", en: VV.AA. La insostenible situación del Derecho Penal, Granada: Comares, 2000, pp. 144 y ss.

${ }^{40}$ GARRIDO, Derecho Penal, Parte Especial, cit. nota n ${ }^{\circ}$ 5, p. 175. Igualmente, a favor de esta teoría, NOVOA, Curso de derecho penal chileno, Tomo II, cit. nota ${ }^{\circ} 2$, pp. 125-6.

${ }^{41}$ POLITOFF / MATUS / RAMÍREZ, Lecciones, cit. nota n 5, p. 310; YÁÑEZ, "Una revisión crítica”, cit. nota $\mathrm{n}^{\circ} 10$, p. 23 y nota 44.
} 
OLAVE, Alejandra "El delito de hurto como tipo de delito de resultado".

custodia ajena. Tratándose de los primeros, el aspecto objetivo del acto de arrogación del contenido de poder correlativo a la posición jurídico formal de propietario consiste en la ruptura y constitución de custodia". ${ }^{42}$

En el hurto, los actos posteriores al momento de la ruptura y constitución de custodia serán parte del agotamiento del delito y no de su consumación. El requerimiento de posibilidad de disposición como marca de éxito para la consumación es uno propio de delitos de apropiación sin ruptura de custodia ajena. ${ }^{43}$

Además de los problemas específicos identificables con la teoría de la disponibilidad, todas las posturas antes señaladas presentan una característica en común: una generalización excesiva que ignora que la custodia sobre la cosa es una relación fáctica, reconocida y dotada de sentido tanto por reglas sociales como de orden jurídico. Como reconoce Oliver, “(...) en la determinación de la existencia de una relación de custodia sobre una cosa no sólo pueden influir consideraciones descriptivas (espaciales), sino también normativas (jurídicas y culturales)". ${ }^{44}$

En efecto, poner énfasis únicamente en la variante espacial de la relación del sujeto con la cosa pierde de vista que dependerá de variados factores si basta con "aprehender el objeto", o "cambiarlo de lugar" para reconocer consumación. Como se dijo anteriormente, la cercanía espacial, el hecho de estar tocando o tomando (aprehendiendo) un objeto, sacarlo del lugar en el que estaba, entre otros, contarán como indicios que permitirán reconocer (o no) una efectiva ruptura de la custodia del dueño o quien legítimamente detente el objeto, y la generación de una nueva custodia de parte de quien, por vía de sustraer el objeto, quebrantó la custodia anterior.

Lo que se deberá determinar es cuándo, tras su proceso de sustracción, "el autor del hurto comienza a ejercer una relación fáctica de dominación de la cosa, que es expresión de su voluntad de dominación, que tendría que ser vencida por el anterior detentador de la cosa, para disponer sobre ella". ${ }^{45}$ Será distinto, entonces, si la acción recae en un objeto sobre el que existe un menor nivel de vigilancia (que está al alcance de cualquier persona, por ejemplo, a causa de confianza, como los objetos que se encuentran dentro de una casa a la que una persona ha sido invitada), que si se ejerce sobre objetos que se guardan con mayor celo, como es el caso en que se cuenta con guardias, cámaras de seguridad y alarmas.

El modelo acá defendido se corresponde con lo que se ha llamado "teoría de la ruptura de custodia y constitución de una nueva", ${ }^{46}$ criticado por Vera por su utilización del concepto

${ }^{42}$ BASCUÑÁN, "Delitos contra intereses instrumentales", Revista de Derecho de la Universidad Adolfo Ibáñez. $I$ (2004), p. 300. Coincidentemente, FERNÁNDEZ, Álvaro, "Hurto-falta", cit. nota n 1, pp. 99-100.

${ }^{43}$ Así, FERNÁNDEZ, Álvaro, "Hurto-falta", cit. nota nº 1, p. 101.

${ }^{44}$ OLIVER, Delitos contra la Propiedad, cit. nota ${ }^{\circ}$ 7, p. 136.

${ }^{45}$ BASCUÑÁN, "Delitos contra intereses instrumentales" cit. nota ${ }^{\circ} 18$, p. 14.

${ }^{46}$ En este punto, el modelo defendido es similar a la llamada "teoría del desapoderamiento y la del apoderamiento", en la que "(...) el delito se integra con dos fases ejecutivas perfectamente diferentes: por una parte, la privación, el desapoderamiento de la víctima y, por otra, la adquisición de dicho poder por parte del hechor" VERA, Juan Sebastián, La consumación, cit. nota $\mathrm{n}^{\circ}$ 4, p. 213, en el sentido de que la completa ruptura de custodia consiste en un "desapoderamiento" y la posterior generación de la nueva custodia, o "relación fáctica de dominación de la cosa", en términos de Bascuñán, consiste en la adquisición de dicho poder. Ahora bien, en la medida en que algunas de estas teorías exigen también posibilidad de ejercer actos dispositivos sobre 
Polit. crim. Vol. 13, № 25 (Julio 2018) Art. 5, pp. 175-207.

[http://www.politicacriminal.cl/Vol_13/n_25/Vol13N25A5.pdf]

de esfera de custodia, tratado más arriba, ${ }^{47}$ y porque se enfoca en la utilización del concepto de sustracción como una adición dogmática al verbo utilizado en el tipo, siendo la sustracción “(...) solo uno de los modos o formas por los cuales se puede realizar la apropiación, pues todos los medios son aptos para consumar el hurto, excepto la violencia." ${ }^{48}$ En cuanto a este punto, sus críticas a la utilización del concepto de sustracción se enfocan en que dicho concepto se centra en la "conducta material" del autor, en cuanto el concepto de apropiación es '(...) un criterio jurídico como es el de considerar 'propia' (dominio) una cosa, apartándose de criterios enteramente fácticos como el 'poder' (apoderarse) o la tenencia de la cosa (sustracción)."49 En este mismo sentido, critica Vera que esta postura conduciría al problema de las "esferas concéntricas", ${ }^{50}$ problema que se daría cuando se constituye un enclave de custodia "dentro" de otro, es decir, al momento en que, sin existir completa ruptura de la custodia de quien detenta legítimamente el bien, el autor comienza a ejercer cierta custodia sobre éste, como en el caso de quien -sin salir del hogar de un tercero- echa el celular que estaba sobre una mesa dentro de su bolsillo. ${ }^{51}$

En efecto y como se señaló inmediatamente arriba, resulta errado utilizar simplemente criterios espaciales con la finalidad de determinar ex ante si es que hubo o no ruptura de custodia y generación de una custodia nueva sobre la cosa. Efectivamente, como reconoce Vera, ${ }^{52}$ el dueño puede decidir ampliar o limitar su custodia sobre la cosa. Así, precisamente el análisis de la extensión y forma en que se ejerce la custodia permitirá determinar el momento de la consumación, que se dará cuando el autor venza por completo el control pretendido por el titular y establezca un nuevo control, apropiándose del objeto. ${ }^{53}$

la cosa, el presente modelo se aparta, ya que no requiere disponibilidad real ni potencial. Se aparta, igualmente, de dichas teorías, en la medida en que éstas no consideran al concepto de custodia como uno de sus elementos esenciales (VERA, Juan Sebastián, La consumación, cit. nota ${ }^{\circ} 4$, p. 217).

${ }^{47}$ Otra de las críticas que plantea, va en la línea de que esta teoría negaría que quien se encuentra persiguiendo a el que le ha sustraído algún bien, se encuentre actuando bajo legítima defensa, toda vez que el delito ya se encontraría consumado (VERA, Juan Sebastián, La consumación, cit. nota $n^{\circ} 4$, p. 220). Es importante señalar que esta posición dista de ser unánime en la doctrina y, si bien no se es tema de la presente investigación, es importante aclarar que el requisito del artículo $10 \mathrm{~N}^{\circ} 4$ de una "agresión" ilegítima, no necesariamente se está refiriendo a un momento previo a la consumación del delito, toda vez que la "agresión actual" y el momento de la consumación pueden no coincidir. Al respecto véase MAÑALICH "La tentativa" cit. nota n 30, pp. 161163 y MAÑALICH, Juan Pablo, “El 'hurto-robo' frente a la autotutela y la legítima defensa de la posesión”, Revista de Estudios de la Justicia 7, (2006), pp. 89 y ss., ambos con ulteriores referencias.

${ }^{48}$ VERA, Juan Sebastián, La consumación, cit. nota $n^{\circ}$ 4, p. 235.

49 VERA, Juan Sebastián, La consumación, cit. nota ${ }^{\circ}$ 4, p. 235.

${ }^{50}$ VERA, Juan Sebastián, La consumación, cit. nota n ${ }^{\circ}$ 4, pp. 219 y ss.

${ }^{51}$ Parte de estas críticas ya han sido respondidas al tratar el concepto de custodia. Véase, supra pp. 5 y ss.

52 VERA, Juan Sebastián, La consumación, cit. nota ${ }^{\circ}$ 4, pp. 220-1.

${ }^{53}$ La postura acá defendida del momento de consumación del hurto coincide parcialmente con la que plantea Vera, que llama de la "disponibilidad potencial", sin perjuicio de las críticas ya planteadas a su postura en el texto principal. El autor reconoce que el delito de hurto se encuentra compuesto por dos fases, una de expropiación y otra de apropiación correlativa, sin caer en el problema de identificar la etapa de expropiación exclusivamente a través un criterio espacial. Ahora bien, el criterio que utiliza para reconocer cuando se ha completado la fase de apropiación es la de ausencia de cualquier elemento que haga suponer a un "espectador imparcial" que la cosa no pertenece al autor. Si bien efectivamente es a través de indicios que se podrá determinar cuando el autor ya se ha apropiado del objeto, incluir como criterio a un "espectador imparcial" trae aparejado una serie de problemas propios de dicho criterio, como lo es la determinación de cuáles son los conocimientos que debe tener al momento de evaluar el comportamiento del autor. Respecto a los problemas 
OLAVE, Alejandra "El delito de hurto como tipo de delito de resultado".

Ahora bien, señala Vera que quienes defienden esta posición respecto al momento de la consumación en el hurto están quitando al dueño la posibilidad de debilitar su custodia al punto de que ella permita que otros comiencen a ejercer cierto nivel de custodia sobre el bien, debiendo afirmar hurto consumado al momento de la generación de una nueva custodia. Precisamente los casos en los que el dueño permite que otros comiencen a ejercer custodia sobre sus bienes son casos en los que no puede afirmarse que exista todavía sustracción. El concepto de sustracción no se refiere a la generación de una nueva custodia sobre el objeto, sino al proceso de ruptura de custodia, proceso que se podrá dar de distintas maneras dependiendo de la forma de custodia que se ejerza sobre el objeto. Así, en casos de falta de custodia, ya sea porque se trata de una especie al parecer perdida, ${ }^{54}$ o porque el dueño ha decidido permitir que cualquiera se haga del objeto, no se podrá reconocer sustracción. En este sentido el concepto de sustracción no trae aparejado los problemas que le imputa Vera, sobre su enfoque en la conducta material de "sacar" o "extraer", sino que dependerá de la forma en que se ejerza la custodia qué deberá reconocerse como indicio de sustracción. Su virtud se encuentra en que permite diferenciar los casos de hurto de aquellos delitos que no requieren sustracción previa a la apropiación, tal como los son el hurto de hallazgo o la apropiación indebida.

Piénsese, a modo de adelanto de la discusión que se verá al final de este trabajo, ${ }^{55}$ en el caso de locales comerciales en los que se permite que las personas lleven sus bolsas o mochilas, saquen los productos de las vitrinas y los introduzcan dentro de dichas bolsas. En este caso, no cabe hablar de sustracción porque no ha habido todavía ruptura alguna de custodia: el dueño ha decidido dejar los objetos a disposición de sus clientes para que ellos los guarden donde les parezca pertinente. ${ }^{56} \mathrm{Si}$, por otro lado, el establecimiento sólo permite que sus clientes introduzcan los productos en carros o canastas pertenecientes a dicho establecimiento (existiendo, por ejemplo, guardias que se preocupen de que así sea), puede reconocerse como indicio de inicio de la sustracción el que una persona utilice un recipiente distinto para dejar los productos, especialmente si se trata de uno en el que el producto no esté a la vista de los otros mecanismos de seguridad.

Así, en ningún caso defender esta postura implica defender que en un caso semejante debería entenderse que existe hurto consumado, defensa que se da sólo en el caso de entender que la custodia debe determinarse exclusivamente desde un punto de vista espacial y que, entonces, la generación de este nuevo espacio de custodia tendría -siempre- que entenderse como ruptura del "mayor" espacio de custodia del establecimiento de autoservicio.

aparejados con la figura del "espectador imparcial”, KINDHÄUSER, Urs, "El tipo subjetivo en la construcción del delito", InDret 4 (2008) pp. 1-35.

${ }_{54}^{54}$ Supra, pp. 5-6.

${ }^{55}$ Infra, pp. 26 y ss.

${ }^{56}$ Sobre este punto resulta interesante el debate que se ha abierto respecto a los llamados "usos apropiatorios", en casos de establecimientos de autoservicio en los que los clientes consumen el producto antes de pagarlo. Si bien el estudio pormenorizado de este problema escapa los alcances del presente trabajo, en la medida en que el establecimiento permite dicha práctica, difícilmente puede afirmarse que exista sustracción de parte del cliente. Para una revisión del problema, optando por la solución de que existiría, de parte del titular, un consentimiento condicionado al pago posterior, véase VERA, Sebastián, La consumación, cit. nota ${ }^{\circ}$ 4, pp. $154-156$. 
Polít. crim. Vol. 13, № 25 (Julio 2018) Art. 5, pp. 175-207.

[http://www.politicacriminal.cl/Vol_13/n_25/Vol13N25A5.pdf]

Quien sustrae y esconde un producto de un local comercial, logrará quebrar la custodia del titular si logra burlar todos los instrumentos de seguridad con los que tal local cuente, dependiendo entonces la ruptura de custodia del nivel de seguridad (así, de cómo el titular del bien decida ejercer su custodia) del establecimiento. Si, por ejemplo, su sustracción fuera detectada por los guardias de seguridad, que lo esperan y detienen al pasar junto a ellos, habrá debilitado, mas no quebrado la custodia. Debilitado, porque estando el hurto en proceso el autor ha establecido cierto nivel de custodia sobre el bien, pero éste sigue estando bajo control de los guardias, es decir, sigue bajo una custodia cuya existencia es ignorada por el autor. En este segundo caso, no podría hablarse de consumación.

La respuesta a la pregunta, en tal caso, de si se trata de tentativa o delito frustrado, dependerá en parte de la posibilidad de aplicar esta última categoría al hurto, lo que es negado por la mayoría de la doctrina, al clasificarlo como un delito de actividad. ${ }^{57}$ Este punto tiene radical importancia, toda vez que el artículo 494 bis que sanciona el hurto falta reconoce en su inciso segundo la posibilidad de que la falta se encuentre frustrada. Lo anterior abre las puertas a cuatro posibles interpretaciones. En primer lugar, afirmar que la mayoría de la doctrina está equivocada al clasificar al hurto como delito de actividad, siendo un delito de resultado en el que es reconocible la frustración. ${ }^{58}$

En segundo lugar, podría defenderse que el hurto es un delito de actividad, pero que ello no obsta a la posibilidad que se dé en calidad de frustrado, toda vez que los delitos de actividad, por regla general, podrán darse en calidad de frustrados. Esta es la posición que defienden Vera y Ramírez. ${ }^{59}$

La tercera posibilidad es una planteada por Oliver, consistente en entender que "frustrada" en términos del art. 494 bis. se utiliza en un sentido distinto del que se utiliza en el art. 7. Apoya su interpretación en el hecho de que el art. 7 habla de crimen o simple delito, mientras que el art. 494 bis tipifica una falta. ${ }^{60}$ Así, "frustración” en el art. 494 bis significaría

\footnotetext{
57 YÁÑEZ, "Una revisión crítica”, cit. nota n 10, pp. 11 y ss.; OLIVER, Delitos contra la Propiedad, cit. nota $\mathrm{n}^{\circ}$ 7, pp. 136 y ss.; HERNÁNDEZ, "La nueva regulación del hurto falta no consumado", La Semana Jurídica, 11 al 17 de Junio, (2007), p. 6 y ETCHEBERRY, Derecho Penal, Parte Especial, cit. nota n ${ }^{\circ}$, pp. 295 y ss. El último, a pesar de no pronunciarse expresamente. Como se verá más adelante (infra, apartado 2.2.), Vera y Ramírez se exceptúan de esta postura, ya que consideran que es posible el hurto en grado de frustrado, a pesar de tratarse de un delito de actividad.

${ }^{58}$ Sin negar que se trata de un delito de actividad, MERA, Jorge, Hurto y robo, Santiago: Jurídica ConoSur, 1995, 181p., pp. 70 y ss. defiende que el hurto en todo caso requiere un resultado para la consumación en el hurto, a saber, un perjuicio patrimonial que es distinguible de la apropiación. Afirma en todo caso que la falta de perjuicio no excluiría necesariamente la inexistencia de responsabilidad, pudiendo sancionarse los casos en que ésta esté ausente como hurto en grado de tentativa o frustrado. Ahora bien, dos párrafos después afirma que el hurto “(...) no exige la producción de un perjuicio”, mas “(...) ello no significa que no se lo requiera para ser sancionado criminalmente” (p. 73), toda vez que ello se opondría al principio de lesividad. Si se considera que el hurto exige el resultado de perjuicio patrimonial, entonces efectivamente se trata de un delito de resultado (aunque en el presente trabajo se niega que el perjuicio patrimonial sea el resultado del delito de hurto). Así, parece contradictorio afirmar el requisito de perjuicio patrimonial como componente del tipo de hurto para luego afirmar que se trata de un requisito de su punibilidad y que no lo exige en el tipo penal.

${ }^{59}$ Véase, infra p. 18.

${ }^{60}$ OLIVER, Delitos contra la Propiedad, cit. nota $\mathrm{n}^{\circ}$, pp. 122 y ss. Cabe señalar que dicho argumento no resulta concluyente, toda vez que a éste se le puede replicar que en el art. 7 se estableció una regla general, la cual encuentra su excepción (punibilidad de la tentativa o frustración de faltas) en el art. 494 bis (así, FERNÁNDEZ, Álvaro, "Hurto-falta, cit. nota n 1, p. 90). Esto se vuelve aún más evidente cuando la conclusión
} 
OLAVE, Alejandra "El delito de hurto como tipo de delito de resultado".

"tentativa", en los términos del art. 7, ya que no sería posible un hurto frustrado. La plausibilidad de esta posibilidad dependerá, por supuesto, de que esté debidamente justificado el hecho de que el legislador haya decidido utilizar, en un mismo cuerpo normativo, la misma palabra en dos sentidos distintos. Ello estaría debidamente justificado si es que efectivamente un hurto frustrado es imposible. De no ser así, se deberá favorecer una interpretación que otorgue el mismo sentido a la palabra "frustrado", utilizada tanto en el art. 7 como en el art. 494 bis.

La última posibilidad es afirmar que el legislador cometió un error al establecer una pena específica al hurto frustrado, por lo que el inciso segundo debiese ser ignorado. Ya que esta última interpretación no resulta compatible con una visión del sistema jurídico que sea fiel al legislador y que se comprometa con la máxima de interpretación útil, vale la pena explorar la distinción entre delitos de actividad y de resultado, para dilucidar a qué categoría pertenece el hurto.

\section{Tipos de delito de actividad y tipos de delito de resultado}

Tradicionalmente la doctrina ha coincidido en asumir la existencia de la distinción entre delitos de actividad y de resultado. El acuerdo general se detiene en ese reconocimiento. Diversas definiciones de ambos conceptos se han esbozado, dando cuenta de una intuición común que existe sobre cuál es el criterio diferenciador entre ambos tipos de delitos.

Tal intuición parece atender a que en los delitos de resultado se reconoce un evento "material" como consecuencia causal de la acción, el que podría llegar a acaecer en tiempo y lugar distintos de los de la completa ejecución de la acción descrita por el tipo en cuestión. Esto se puede ver a propósito del delito de homicidio (considerado como ejemplo paradigmático de delito de resultado). Si A dispara su arma contra $\mathrm{B}$ en un tiempo $\mathrm{t}_{1}$, causando su posterior muerte por desangramiento en un tiempo $\mathrm{t}_{2}$, A ha finalizado la ejecución de su acción en $\mathrm{t}_{1},{ }^{61}$ a pesar de que al momento de disparar (i.e. al momento de jalar el gatillo), la muerte de B no se haya producido. Así, B muere en tiempo y lugar distintos de aquéllos en que la acción de A fue ejecutada.

de Oliver es que con "frustrado" el legislador se refiere a "tentativa" en los términos del art. 7, toda vez que al definir la tentativa en su inc. 3ro, el art. 7, también se refiere a crímenes o simples delitos y no a faltas.

${ }^{61}$ Existe discusión en el contexto de la filosofía de la acción sobre si efectivamente el "disparar contra B" (the shooting) y el "matar a B" (the killing) son descripciones de la misma acción. La disputa, presentada por Bennett (BENNET, Jonathan, Events and their names, Oxford: Oxford University Press, 1988, pp. 194 y ss.), se centra en dos argumentos. El de la actio praecox, que defiende que una acción no puede estar finalizada antes de que el resultado que la describe se verifique y el del no further effort que, en contra del argumento de la actio praecox, afirma que se puede decir que una acción está finalizada, si es que ya no le queda al agente nada más por hacer. La solución propuesta por Bennett, basada en la fuerza del argumento del no further effort, va por el camino de introducir la noción de consumación. Es correcto decir que la ejecución de la acción de A de matar a B está terminada cuando A finaliza el disparo, a pesar de que B no esté muerto, porque lo que resta no es la acción de A, sino que dicha acción adquiera una particular propiedad (o "que se consume", en los términos de Bennett), a saber, que efectivamente B muera. El que un evento cambie o adquiera una propiedad en el tiempo no tiene nada de extraño: “(...) es como afirmar 'En 1949 el ex-actor que habita en la Casa Blanca vivía en California, pero no era todavía un ex-actor." BENNET, Events, cit. nota $n^{\circ} 33$, p. 198. Traducción propia. Asimismo, MAÑALICH, Norma, causalidad y acción, Madrid: Marcia Pons, 2014, pp. 16 y ss. y nota 60. Un análisis exhaustivo acerca de este problema se encuentra en LOMBARD, Lawrence, "Actions, results, and the time of a killing", Philosophia Vol. 8 n²-3, (1978), pp. 341-354. 
Polit. crim. Vol. 13, № 25 (Julio 2018) Art. 5, pp. 175-207.

[http://www.politicacriminal.cl/Vol_13/n_25/Vol13N25A5.pdf]

La distinción entre delitos de actividad y delitos de resultado parece clara en el ejemplo del homicidio, mas dista de serlo. Atender a elementos materiales (o físicos) como criterios de distinción, (tales como el que exista "una alteración física en el mundo exterior", ${ }^{6}$ que la acción ejecutada sea previa ${ }^{63}$ o que la acción ejecutada pueda ser entendida como causa y el resultado como efecto ${ }^{64}$ ) trae aparejada una serie de problemas.

Esto lo nota Roxin, que llega a la poco feliz conclusión de que la distinción atiende a una cuestión de hecho.

"Hay que tener claro que no todos los tipos se pueden encuadrar claramente en los delitos de resultado o de actividad, sino que a veces hay que distinguir caso por caso: así las lesiones ( $\$ 223$ ) son un delito de mera actividad si consisten en una bofetada, pero son un delito de resultado si se producen lanzando una piedra." 65

Siguiendo con su razonamiento, Roxin tendría que afirmar que si es que se intenta abofetear a otra persona sin acertar el golpe, se estaría ante una tentativa acabada (delito frustrado) de lesiones, ya que sólo en los delitos de resultado existe la posibilidad de tentativa inacabada (tentativa) ${ }^{66}$ solución que resulta a lo menos poco intuitiva, considerando que en el caso del que tira una piedra sin acertar podría sin más reconocerse tentativa acabada. ${ }^{67}$

Similares problemas se pueden encontrar al intentar plantear la distinción desde el punto de vista de que, en los delitos de resultado, la acción produciría como resultado cambios en el mundo espacio-temporalmente diferenciados de ésta. Acá, lo importante está en la noción de un cambio "espacio-temporalmente diferenciado". Siempre un delito de resultado producirá un cambio: una modificación perjudicial. El punto está en dilucidar si se puede reconocer delitos que produzcan una modificación perjudicial como resultado, sin que ésta sea una modificación espacio-temporalmente diferenciada. ${ }^{68}$ Ahora bien, resulta pertinente advertir que el concepto de modificación perjudicial no se corresponde con el concepto de lesión.

\footnotetext{
${ }^{62}$ NOVOA, Curso de derecho penal chileno, Tomo I, 3a ed. Santiago: Editorial Jurídica, 2005, p. 246.

63 “(...) debe observarse que el problema de la relación causal debe plantearse entre una acción (suponemos previamente, en consecuencia que ha existido un comportamiento y una voluntad finalista) y un resultado." (Énfasis en el original). ETCHEBERRY, Derecho Penal, Parte General, Tomo II, $3^{a}$ ed. Santiago: Editorial Jurídica, 1997, p. 187.

64 "Acción y resultado son cosas distintas, como que una es la causa y el otro el efecto." (Énfasis en el original). CURY, Derecho Penal, cit. nota n ${ }^{\circ}$ 2, p. 263.

${ }^{65}$ ROXIN, Claus, Derecho Penal, Parte General, Tomo I, $2^{a}$ ed. Madrid: Civitas, 1997, p. 329.

66 "[E]n ellos [los delitos de actividad] también coincide la tentativa acabada (o sea, el momento en el que el autor ha hecho todo lo necesario para provocar el resultado) con la consumación del delito." ROXIN, Claus, Derecho Penal, cit. nota ${ }^{\circ}$ 67, pp. 328-9.

${ }^{67}$ El § 223 del Código Penal alemán prevé 2 variantes del delito de lesiones, el maltrato corporal y el daño a la salud. Roxin podría estar refiriéndose a esta primera variante cuando afirma que una bofetada consistiría en un delito de actividad. Incluso aceptando que Roxin se refiere, más que a una cuestión acerca de la forma de ejecución del tipo en un caso particular, a la descripción típica del delito de lesiones contenida en el StGB (que en todo caso consistirían en un delito de resultado, véase infra pp. 16 y ss.), las conclusiones acá expuestas siguen siendo las mismas.

${ }^{68}$ Vera reconoce la existencia de resultados de carácter "inmaterial o normativo", "cuya comprobación se extrae luego de valorar situaciones jurídicas", mas reconoce que dichos resultados serían un efecto de la conducta, claramente distinguibles y vinculados a ésta mediante una relación de causalidad (VERA, Juan Sebastián, $L a$ consumación, cit. nota $\mathrm{n}^{\circ} 4$, pp. 77 y ss.).
} 
OLAVE, Alejandra "El delito de hurto como tipo de delito de resultado".

Así, los delitos de peligro, en la medida en que sean reconocidos como delitos de resultado, igualmente generan una modificación perjudicial.

Bajo esta concepción de la distinción entre delitos de actividad y de resultado, la imposibilidad conceptual en el hurto de separar la acción del autor de la sustracción requerida en el tipo (su resultado, como se verá más adelante), hace inevitablemente clasificarlo bajo la categoría de delitos de actividad.

"Es indudable que la conducta de apropiación tiene efectos que podrían sugerir la presencia de un resultado (...). Pero para que esos efectos técnicamente constituyan un resultado típico se requiere que, además de ser exigidos por la ley, sean distinguibles y separables de la conducta misma". ${ }^{69}$

En efecto, como reconoce Hernández, si se mira a la acción realizada como, por ejemplo, el movimiento de la mano al tomar un objeto y dejarlo en un bolsillo, el acto de apropiarse es indistinguible del movimiento corporal. La pregunta es si debiera observarse lo realizado para distinguir entre delitos de actividad y resultado, considerando los problemas antes mencionados que acarrea este enfoque. Éstos aparecen cuando se confunden categorías, aplicando la distinción entre actividad y resultado a lo realizado en vez de aplicarla a la descripción, en este caso, el tipo. De ahí que resulta más preciso utilizar las categorías de tipos de delito de actividad y resultado, evitando entonces una posible confusión entre la descripción típica y aquello subsumido (lo realizado por el autor) bajo dicha descripción. ${ }^{70}$

Un tipo de delito de resultado, entonces “(...) especifica un estado cuya producción, destrucción, prevención o preservación constituye el resultado de cada acción que ejemplifica el correspondiente tipo de acción. Ello quiere decir, empero, que semejante resultado no constituye un componente de la acción en cuestión, sino sólo de su descripción." 71 Esta descripción contenida en el tipo especifica una acción que concluye con una modificación, producción o destrucción de un determinado estado. Por contraste, la descripción de actividades no incluirá la referencia a una modificación, producción o destrucción de un determinado estado.

\subsection{Acciones y actividades}

La caracterización anterior de tipos que describen acciones se corresponde con el trabajo hecho por Zeno Vendler ${ }^{72}$ para distinguir entre descripciones (usos de los verbos) de lo que

\footnotetext{
${ }^{69}$ HERNÁNDEZ, “La nueva regulación”, cit. nota $n^{\circ}$ 59, p. 7. Énfasis en el original. Asimismo, clasificando al hurto como delito de actividad, CURY, Enrique, "Contribución a la distinción entre delitos de resultado y de simple actividad” Revista de Ciencias Penales XL, vol. 1, (1993), p. 17, quien afirma que "(...) los procesos causales posteriores al comportamiento mismo del sujeto activo escapan a su injerencia directa, y él sólo puede dirigirlos mediatamente. Pues bien, en ese conjunto de encadenamientos no dominados inmediatamente por la actividad del autor y que, sin embargo, son exigidos por el tipo del homicidio para la consumación del delito, consiste el resultado." Énfasis en el original.

${ }^{70}$ La nomenclatura propuesta simplemente busca evitar la ambigüedad respecto a si las categorías delito de actividad y delito de resultado se refieren a lo realizado por el autor o a la descripción típica, independiente de la conducta específica del autor en cada caso.

${ }^{71}$ MAÑALICH, Norma, cit. nota ${ }^{\circ} 33$, p. 16. Énfasis en el original.

72 VENDLER, Xeno, Linguistics in Philosophy 3 a ed. Ithaca: Cornell University Press, 1974, pp. 97 y ss.
} 
Polit. crim. Vol. 13, № 25 (Julio 2018) Art. 5, pp. 175-207.

[http://www.politicacriminal.cl/Vol_13/n_25/Vol13N25A5.pdf]

llama "términos de actividad" (actividades) y "términos de resultado" (acciones). ${ }^{73}$ Las primeras consisten en procesos cuya descripción no requiere del cumplimiento de nada más que la realización del proceso mismo. Dentro de este grupo se encuentran verbos como correr o manejar.

Las segundas, por su parte, describen procesos que requieren un resultado. Así, mientras de quien está manejando se puede predicar que ha manejado, quien está en proceso ganar una carrera, no la ha ganado. De ahí que se suela decir, de quien va primero en la carrera "va ganando". Sólo si el resultado ya se presenta como inevitable comienza a tener sentido la expresión "ya ganó", utilizada antes de la llegada del competidor en cuestión a la meta. ${ }^{74}$

Los estados, por último, no admiten ser calificados como acciones aunque se caracterizan por perdurar en el tiempo. A pesar de adquirirse conforme a cambios, no se desempeñan de forma dinámica en lapsos de tiempo. Por ello, una oración como "entre jueves y viernes estaré sabiendo álgebra" no tiene sentido. Esta falta de desempeño dinámico en el tiempo es lo que caracteriza, por ejemplo, a los delitos de posesión. Utilizando el mismo ejemplo, tampoco tiene sentido decir "entre jueves y viernes estaré poseyendo un libro". ${ }^{75}$

Para los efectos de la distinción entre tipos de delito de actividad y de resultado, habrá que enfocarse en la distinción entre actividad y acción. Con diferente denominación, pero desde el mismo punto de vista, Kenny explora la diferencia.

“Para algunos de estos verbos, cualquier afirmación con la forma 'A está øndo' implica una afirmación con la forma 'A no ha ødo'; para otras, no lo implica. Por ejemplo, si un hombre está construyendo una casa, no la ha construido todavía". ${ }^{76}$

La diferencia entre actividades y acciones radica en la condición de homogeneidad que cumplen las primeras y que no cumplen las segundas. Ésta se puede explicar de la forma que sigue: quien realiza una actividad entre tiempo $t_{1} \mathrm{y}_{\mathrm{t}}$, la ha realizado igualmente en el tiempo

\footnotetext{
${ }^{73}$ Tanto Vendler como Kenny (KENNY, Anthony, Action, Emotion and Will, London: Routledge, (2003), p. 120 y ss.), que posteriormente trata el mismo tema, ponen el énfasis de su análisis en tipos de verbos, entendiendo que son los verbos en sí mismos los que ejemplifican actividades, acciones o estados. Es por esto que en la terminología original de Vendler se habla de términos de actividad (activity terms) y términos de resultado (accomplishment terms). Como evidencia Mourelatos (MOURELATOS, Alexander, "Events, processes, and states", Linguistics and Philosophy n ${ }^{\circ} 2$, (1978), pp. 418 y ss.), esta comprensión tiene falencias. Mourelatos hace notar que la distinción no es entre verbos, toda vez que un mismo verbo puede designar actividades o acciones, sino entre aspectos verbales, esto es, cómo ciertas propiedades de los verbos denotan el comportamiento de una acción, actividad o estado en el tiempo. Por ello se ha decidido modificar la terminología original, utilizándose en adelante "actividad" y "acción".

${ }^{74}$ Véase supra nota 61.

${ }^{75}$ Este punto es pasado por alto por Cox quien clasifica a los delitos de posesión como delitos de actividad. COX, Juan Pablo, Delitos de Posesión, Montevideo y Buenos Aires: BdF, 2012, pp. 186 y ss., Una crítica a este planteamiento se encuentra en MAÑALICH, Norma, cit. nota ${ }^{\circ} 33$, nota 47.

76 Traducción propia. Original: "[f]or some of these verbs, any statement of the form 'A is øing' implies a statement of the form 'A has not ød'; for others it does not. For instance, if a man is building a house, he has not yet built it". KENNY, Anthony, Action, cit. nota n ${ }^{\circ} 75$, p. 121. Por las formas "øndo" y "ødo" debe entenderse, respectivamente, el gerundio y el participo del verbo específico que se utilice en remplazo de la fórmula general.
} 
OLAVE, Alejandra "El delito de hurto como tipo de delito de resultado".

$\mathrm{t}_{2},{ }^{77}$ mientras quien inicia una acción en tiempo $\mathrm{t}_{1}$ que culmina con un determinado evento en $t_{3}$, no ha realizado el resultado (no se ha dado el evento) en el tiempo t2. Estando ante una actividad, una vez iniciado el proceso, éste ya se encuentra consumado, en el sentido de que ya se ha realizado la actividad descrita.

La distinción planteada por Vendler y Kenny da luces acerca de la distinción entre tipos de delito de resultado y de actividad. La acción descrita por un tipo de delito de resultado es susceptible de ser descrita como la acción productiva o destructiva de un determinado resultado. Dicho resultado cuenta como la "marca de éxito" de la acción, marca exigida por el tipo. La actividad descrita por un tipo de delito de actividad, en cambio, no incluye la producción o destrucción como resultado. Ella se completa al realizar la actividad, sin que se requiera modificación ulterior alguna. Esto quiere decir que, en un delito de actividad, si es que "el delincuente pone de su parte todo lo necesario para que el crimen o simple delito se consume", éste se consumará, salvo que -como se verá más adelante- haya sido imposible la consumación desde el principio.

\subsection{Excurso: ¿la frustración en los delitos de actividad?}

Lo anterior explica por qué se ha negado, por la mayoría de la doctrina en Chile, la posibilidad de una tentativa acabada en delitos de actividad. Si es que se observa desde el punto de vista del desistimiento, hay una imposibilidad de desistimiento activo en el caso de que el tipo describa una actividad. ${ }^{78}$ La tentativa acabada de un delito de actividad no puede ser susceptible de desistimiento, porque si el autor ha creído poner de su parte todo lo necesario para que el delito de actividad se consume, entonces asumirá que el delito se consumó, representación que es incompatible con la representación de la existencia de una posibilidad de impedir la consumación, propia del desistimiento. Si, por otra parte, notó la imposibilidad de consumación, entonces ya se habrá representado su actuar como fallido y, por lo tanto, no susceptible de desistimiento.

Ahora bien, no es unánime en Chile la posición que afirma que es imposible que un delito de actividad se dé en grado de frustrado. Ramírez y Vera han defendido dicha posibilidad. Desde posturas similares, ambos plantean la posibilidad de distinguir la ejecución de la conducta típica de la consumación, pudiendo entenderse que en los casos de frustración, la ejecución de la conducta típica consiste en "(...) una etapa más avanzada en el camino hacia la perfección del delito o hacia a la consumación, que sea objetivamente más grave que la tentativa."79 Así, existiría frustración en los delitos de actividad "(...) cuando se encuentra el sujeto activo llevando a cabo la última etapa de ejecución de la conducta y se interrumpe en el punto que de haberla concluido no habría requerido de la realización de un acto posterior para su consumación." ${ }^{80}$ Esta postura, sin embargo, resulta contraria a lo defendido hasta

\footnotetext{
77 "Si es verdadero que alguien ha estado corriendo por media hora, entonces debe ser verdadero que ha estado corriendo durante cada período dentro de esa media hora." VENDLER, Linguistics, cit. nota n 74, p. 101. Traducción propia.

${ }^{78}$ En este sentido, CURY, “Contribución a la distinción”, cit. nota n 71, pp. 73-4.

${ }^{79}$ VERA, Juan Sebastián, "La frustración en los delitos de mera actividad”, Revista de Estudios Ius Novum 1 , (2008), p. 252.

${ }^{80}$ RAMÍREZ, Cecilia, "La frustración en delitos de mera actividad a la luz de determinadas sentencias", Revista de Derecho de la Pontificia Universidad Católica de Valparaíso XXVI, (2005), p. 141.
} 
Polit. crim. Vol. 13, № 25 (Julio 2018) Art. 5, pp. 175-207.

[http://www.politicacriminal.cl/Vol_13/n_25/Vol13N25A5.pdf]

ahora, en particular respecto a que considera concebible que alguien comience a realizar una actividad $\mathrm{y}$, sin embargo, sea interrumpido, sin llegar a ejecutarla. ${ }^{81}$

Quien desee evitar la realización de una actividad sólo debe abstenerse de comenzar (o evitar que otro comience) a realizarla, ya que una vez comenzada ésta ya se habrá realizado y se seguirá realizando hasta que el sujeto se detenga (siendo, entonces, imposible interrumpirla "después" de su inicio pero "antes" de que se consume). Es por esta característica que, en el caso de las actividades, al igual que los estados, la situación particular del sujeto al momento de seguir la norma es la que definirá si su deber es de actuar o de abstenerse, sin poder identificarse ya en la descripción típica, como sí ocurre en el caso de las acciones. Así, para seguir la norma que prohíbe la actividad de conducir en estado de ebriedad, el sujeto deberá omitir manejar en tal estado o, en caso de ya encontrarse manejando, realizar la acción de detenerse. ${ }^{82}$

Ahora bien, esta particularidad de los delitos de actividad, de que una vez comenzada la ejecución (existiendo oportunidad para la acción ${ }^{83}$ ), la actividad ya se realizó, no implica que sea imposible un delito de actividad en grado de frustrado. Para ejemplificarlo con un caso: una persona que, con la finalidad de tener "una noche memorable" se inyecta lo que cree ser alcohol en la sangre (tratándose, en realidad, de una solución salina) y sale a manejar inmediatamente después de administrada la dosis, pone "de su parte todo lo necesario para que el crimen o simple delito se consume" y las causas por las que el delito de manejo en estado de ebriedad no se consuma son efectivamente "independientes de su voluntad". 84

Por razones de extensión, no se ahondará en el análisis de los delitos de actividad frustrados. Ello, porque debe negarse la clasificación del hurto como un delito de actividad. La razón se encuentra en el verbo ${ }^{85}$ que se utiliza en el tipo: "apropiar". Es el apropiarse de una cosa mueble ajena lo que exige el tipo para su consumación, lo que, como fue tratado anteriormente, requiere de un proceso que culmine con la constitución de una nueva custodia sobre el objeto, correspondiéndose con un resultado. Así, utilizando los ejemplos explicados anteriormente, resultaría anómalo decir que alguien que se está apropiando de algo, ya se ha apropiado. Más bien, quien se está apropiando de algo, está en proceso de conseguirlo, mas aún no lo ha logrado, lo que lleva a clasificar al hurto como un delito de resultado.

\footnotetext{
${ }^{81}$ Además de utilizar el ejemplo del hurto como delito de actividad, Ramírez y Vera utilizan como ejemplos de delitos de actividad la violación y la injuria, respectivamente. Si bien la doctrina nacional es mayoritaria en cuanto a que son delitos de actividad, en ambos casos esto se puede poner en duda. En cuanto a la injuria, bajo la tesis de que ella tiene como exigencia la puesta de conocimiento de su realización por parte de un sujeto distinto del autor, ésta consistiría en un tipo de delito de resultado (causalmente condicionado). Así, KERN, Eduard, Los delitos de expresión, Buenos Aires: Depalma, 1967, 228p, pp. 54, 62 y ss., y MAÑALCH, “¿La comisión de delitos mediante la imputación de delitos?, Revista peruana de doctrina y jurisprudencia penales 6, (2005), pp. 208 y ss. La violación, por su parte y bajo el modelo acá defendido, puede entenderse como un tipo de delito de resultado, toda vez que el acceso carnal puede ser entendido como el resultado intrínseco (constitutivamente complejo) de la acción (al respecto, infra, pp. 20 y ss.). Así, MAÑALICH, "La violación como delito de propia mano", Revista de Ciencias Penales XLIII, n 4, (2016), pp. 43-4.

${ }^{82}$ Esto es lo que Mañalich llama la opacidad silogística de ciertas normas. MAÑALICH, Norma, cit. nota $n^{\circ}$ 33 , pp. 12 y ss.

${ }^{83}$ Véase, infra pp. 22 y ss.

${ }^{84}$ En este (y en todos los casos de delito de actividad frustrado) se está ante una "tentativa inidónea". Véase infra pp. 25-26.

${ }^{85} \mathrm{O}$, más precisamente, en el aspecto verbal (véase nota 43).
} 
OLAVE, Alejandra "El delito de hurto como tipo de delito de resultado".

De esta forma, lo planteado por Vendler y Kenny se diferencia de lo que se ha entendido tradicionalmente como delito de resultado al permitir afirmar que existen casos en que sin que exista un resultado espacio-temporalmente separado de la acción, vinculada a ésta por medio de una relación de causalidad, pueden reconocerse en todo casos acciones y resultados, esta vez no separados causalmente de la acción. Lo anterior no está exento de dificultades. En la próxima sección se analizará cómo puede reconocerse un resultado a pesar de que éste no se corresponda con una modificación espacio-temporalmente diferenciada de la acción. Ello requerirá introducir una nueva distinción, entre descripciones causalmente complejas y constitutivamente complejas.

\subsection{Descripciones causalmente complejas y constitutivamente complejas}

Las acciones susceptibles de describirse como acciones productivas de un determinado resultado pueden ser de dos tipos, dependiendo de la relación que exista entre acción y resultado. Considérense los números (3), (4) y (5) en el ejemplo que propone Goldman:

"Supóngase que John hace cada una de las siguientes cosas: (1) mueve su mano, (2) asusta a una mosca, (3) mueve su reina a d7, (4) hace un jaque mate a su oponente, (5) le genera un ataque cardíaco a su oponente, y (6) gana su primer juego de ajedrez." 86

Ciertamente sería anómalo, en este caso, decir que el movimiento de la reina causa un jaque mate. En cambio, no hay problema en afirmar que el ataque cardíaco del oponente de John es causado por el movimiento de la reina. Esta particularidad se explica por la distinción entre dos tipos de descripciones; causalmente complejas, en las que se describe una relación causal entre acción y resultado, y constitutivamente complejas, en las que la relación entre acción y resultado depende de la existencia de ciertas reglas que permitan reconocer dicho resultado. ${ }^{87}$

En ambos tipos de descripciones lo que se llama "resultado" no es más que un elemento de una descripción más compleja de la misma acción. ${ }^{88}$ Esto es lo que se conoce, desde Feinberg, ${ }^{89}$ como el efecto acordeón. Así, el acordeón se corresponde con la acción, el que puede estirarse o encogerse según los aspectos de la acción que decidan incluirse en la descripción de ésta. La acción de John, por lo tanto, puede describirse como el movimiento de la mano de John a través del cual mueve su reina o, expandiendo el acordeón, como el movimiento de la mano de John que le genera un ataque cardiaco a su oponente. Como lo

\footnotetext{
${ }^{86}$ GOLDMAN, Alvin, A theory of human action. New Jersey: Prentice-Hall, 1970, p. 1.

${ }^{87}$ SEARLE, Making the social World, Oxford: Oxford University Press, 2010, pp. 36 y ss.

${ }^{88} \mathrm{El}$ reconocimiento de que en este caso se trata de una sola acción supone un compromiso con una tesis extensionalista para la individuación de acciones, la que, a diferencia de una tesis intensionalista, no reconoce acciones según tipos instanciados. MAÑALICH, Norma, cit. nota $n^{\circ} 33$, pp. 46 y ss.; SEARLE, John, La construcción de la realidad social, Barcelona: Paidós, 1997, p. 36.; Asimismo, GOLDMAN, Alvin, A theory, cit. nota $\mathrm{n}^{\circ} 88$, quien, a pesar de reconocer la distinción acá planteada, lo hace desde la vereda contraria, al considerar que diversas descripciones de lo que acá se considera una misma acción (A disparó contra B, A mató a B) se corresponderían con distintas acciones (acción 1: A disparó contra B. Acción 2: A mató a B). Para una crítica a la visión de Goldman, véase BENNET, Events, cit. nota n 63, pp. 191 y ss. y LOMBARD, "Actions", cit nota $n^{\circ} 63$, pp. 350 y ss.

${ }^{89}$ FEINBERG, Joel, Doing and deserving, Princeton: Princeton University Press, 1970, p. 132 y ss.
} 
Polit. crim. Vol. 13, № 25 (Julio 2018) Art. 5, pp. 175-207.

[http://www.politicacriminal.cl/Vol_13/n_25/Vol13N25A5.pdf]

plantea Davidson, “(...) [e]xisten, de hecho, un gran número de melodías que podemos tocar en el acordeón". 90

La diferencia entre clases de descripciones complejas de acciones, como ya se dijo, se refiere a la forma en que se relacionan las dos descripciones de la misma acción. En el caso de las descripciones causalmente complejas, ambas están en relación de causa y efecto, mientras que en el de las descripciones constitutivamente complejas, la relación entre las distintas descripciones no depende de reglas de causalidad, sino de una estructura institucional que permite el reconocimiento del resultado como tal. Así, sería imposible hablar de jaque mate si es que no existiera el juego del ajedrez y un conjunto de reglas que permiten reconocer cierto movimiento de un pedazo de madera con determinada forma (la reina, en este caso) como un jaque mate.

El reconocimiento de que el movimiento de cierto pedazo de madera, en el ejemplo del ajedrez, cuenta como un jaque mate, depende de la existencia de instituciones que, a través de reglas, otorgan el estatus de jaque mate a ese movimiento en particular. Lo que permite el reconocimiento de este nuevo estatus asignado a un fenómeno es lo que Searle ${ }^{91}$ llama un "hecho institucional", cuya existencia es dependiente de las reglas que le otorgan dicho estatus, llamadas reglas constitutivas, las que "(...) crean la posibilidad misma de ciertas actividades". 92

Gracias a las reglas constitutivas se puede reconocer que ciertos movimientos de piezas cuentan como jugar ajedrez o que en ciertos contextos alzar una mano cuenta como votar. En este caso no se trata de una relación causal entre la acción y el resultado: el que un representante levante la mano durante una votación no causa un voto, sino que lo constituye. La mano levantada puede describirse como la emisión de un voto, gracias a determinadas reglas que permiten reconocer que dicha persona está investida de autoridad para votar en el contexto en que una votación a mano alzada está llevándose a cabo.

A diferencia de las reglas constitutivas, las llamadas "reglas regulativas" regulan actividades o acciones cuyo acaecimiento es independiente a la existencia de dichas reglas. Esto quiere decir: las actividades o acciones son reguladas a través de este tipo de reglas pero no constituidas por ellas, por lo que si las reglas regulativas dejaran de existir, tales actividades o acciones seguirían siendo reconocibles. ${ }^{93}$ Así, la función de las reglas regulativas es instrumental: contribuyen a un mejor desarrollo de la práctica.

En la terminología antes planteada, un hecho institucional permite el reconocimiento de descripciones como constitutivamente complejas: una segunda descripción que incluye como componente un resultado conectado no causalmente a la descripción de la acción.

\footnotetext{
${ }^{90}$ DAVIDSON, Donald, Essays on actions and events, Oxford: Oxford University Press, 2002, p. 53.

${ }^{91}$ SEARLE, John, La construcción, cit. nota ${ }^{\circ} 90$, pp. 49 y ss.

${ }^{92}$ SEARLE, John, La construcción, cit. nota $\mathrm{n}^{\circ}$ 90, p. 45.

${ }^{93}$ Esto no significa que el reconocimiento de un hecho bruto sea independiente a todas las instituciones, en particular al lenguaje. De hecho, la distinción misma entre hechos brutos y hechos institucionales encuentra ciertos límites que dificultan su diferenciación. Véase, SEARLE, John, La construcción, cit. nota n ${ }^{\circ} 90$, pp. 76 y ss. HART, H.L.A., El Concepto de Derecho, Buenos Aires: Abeledo Perrot, 2007, pp. 110 y ss. Para efectos de este trabajo no será necesario ahondar en dichos límites.
} 
OLAVE, Alejandra "El delito de hurto como tipo de delito de resultado".

Utilizando una terminología diferente, pero en el mismo sentido, Kindhäuser, ${ }^{94}$ plantea la distinción entre juicios teóricos, que constatan y explican hechos brutos, y juicios prácticos, que se corresponden con juicios de valor que constatan propiedades no naturales, sino convencionales de los objetos, de acuerdo a reglas sociales. A través de juicios prácticos se adscriben propiedades convencionales a hechos brutos que permiten reconocerlos como hechos procesados. Dichas propiedades convencionales no suman algo sustancial al hecho bruto, sino que permiten reconocerlo como algo diferente (como un hecho institucional, en la terminología de Searle).

"Aquello de más que poseen los hechos procesados frente a los brutos no tiene que referirse a algo sustancial, sino que también puede consistir en una función lingüística. Bien mirado el asunto, resulta evidente, por ejemplo, que un escrito no se conoce como documento, sino que se reconoce como tal. Aquello de más no es, entonces, algo que es, sino algo que debe ser."

Lo requerido para reconocer esta segunda descripción es un contexto: una oportunidad para la ejecución de la acción. ${ }^{95}$

Tal como es lógicamente necesario que exista cierto estado de cosas para destruirlo (o que no exista para crearlo, como que una ventana esté cerrada para abrirla), ${ }^{96}$ existen ciertas condiciones necesarias para la realización de una acción ( $\mathrm{y}$, en este caso, para la realización de una acción constitutivamente compleja). Por ejemplo, quien desee votar alzando su mano, sólo lo logrará si hay una votación en curso, la votación se realiza a mano alzada y se tiene derecho a voto. $\mathrm{Si}$, por ejemplo, una persona acude como particular (no representante) a una sesión de un concejo municipal, no importa cuánto levante la mano al momento de cada votación, su acción no será constitutiva de "votar", sino sólo admitirá la descripción del hecho bruto de "alzar la mano".

Volviendo al ajedrez, el jugador que haya confundido al rey de su oponente con el alfil del mismo, intentando realizar un jaque mate a este último, sólo habrá logrado atrapar al alfil entre algunas piezas, pero no habrá hecho en ningún caso un jaque mate. En ambos ejemplos lo que está ausente para poder reconocer la segunda descripción que incluye al resultado como componente es la oportunidad para realizar la acción: en el primer caso, falta que la persona que desea votar esté investida de la autoridad para hacerlo; en el segundo, que se encierre a la pieza correcta (no al alfil, sino al rey).

Lo importante del concepto de oportunidad para la acción, en el caso de acciones constitutivamente complejas, es que ejecutada la acción existiendo la oportunidad correspondiente, el acaecimiento del resultado es necesario. Esto quiere decir: si existe oportunidad para la acción y dicha acción se ejecuta, el resultado siempre se dará. Así, si quien va al concejo municipal fuera un concejal, su acción de alzar la mano sí contaría como un voto. Ya que la conexión en este tipo de acciones entre la acción y el resultado no es

\footnotetext{
${ }^{94}$ KINDHÄUSER, "Hechos brutos y elementos normativos del tipo", InDret 2, (2014), pp. 12-3.

${ }^{95}$ VON WRIGHT, Georg Henrik, Norma y Acción, Madrid: Tecnos, 1970, pp. 54-5.

${ }^{96}$ VON WRIGHT, Norma y Acción, cit. nota n 97, pp. 54-5; KINDHÄUSER, "Hechos brutos", cit. nota n 60, p. 55
} 
Polit. crim. Vol. 13, № 25 (Julio 2018) Art. 5, pp. 175-207.

[http://www.politicacriminal.cl/Vol_13/n_25/Vol13N25A5.pdf]

causal, si existe el contexto adecuado, es decir, si existe la oportunidad para la acción, siempre podrá reconocerse el resultado.

A diferencia de las descripciones causalmente complejas en las que la conexión entre acción y resultado es contingente (extrínseca), en las constitutivamente complejas la conexión entre acción y resultado es necesaria (intrínseca). Esto último ayuda a explicar por qué existe dificultad para calificar como tipos de resultado a aquellos que contienen descripciones de producciones de resultados constitutivamente complejos. Pues cuando se habla de resultados, parece existir una intuición favorable a la necesidad de que se trate de modificaciones espacio-temporalmente diferenciables de la acción, que no requieran de una estructura institucional para reconocerse. Como nota Searle:

"La íntima sensación que experimentamos, de acuerdo con la cual hay un elemento mágico, un truco de conjuro, un juego de prestidigitación, en la creación de hechos institucionales a partir de los hechos brutos, deriva del carácter no físico, no causal de la relación entre los términos $\mathrm{X}$ e $\mathrm{Y}(\ldots)$. En nuestros momentos metafísicamente más tercos no renunciamos a preguntarnos 'Pero, ¿es realmente un $\mathrm{X}$ un Y?'. Por ejemplo, ¿son estos trozos de papel realmente dinero? ¿Es esta extensión de terreno realmente propiedad privada de alguien? Hacer ciertos ruidos en una ceremonia, ¿es realmente casarse?". 97

Como ya se ha visto, no existen razones (sino, como explica Searle, momentos metafísicamente tercos) para reconocer como descripciones de acciones resultativas únicamente a las que concluyan con una modificación, producción o destrucción causalmente condicionada de un determinado estado. Existiendo oportunidad para la acción, la ejecución de un jaque mate en el ajedrez tiene como resultado (intrínseco) el que la partida termina y uno de los jugadores se corona vencedor. En el caso del hurto, existiendo oportunidad para la acción, la sustracción de una cosa mueble ajena con ánimo de apropiación por parte del autor, tiene como resultado (intrínseco) la ruptura de custodia ajena y la constitución de una nueva custodia sobre el bien.

Así, esta reconstrucción del hurto impide que sea entendido como una actividad, toda vez que la apropiación (completa ruptura con constitución de nueva custodia) puede fijarse en un punto específico de tiempo y no durante un lapso de tiempo. Tal como ganar una carrera, hay un punto en el tiempo en que se puede decir que el sujeto se apropió de una cosa mueble ajena, punto distinguible del lapso de tiempo en que está llevando a cabo el proceso de apropiarse de ella. Esto es lo que lo distingue de las actividades, en las que dicha distinción no es posible (por su condición de homogeneidad). ${ }^{98}$

La conclusión anterior es incompatible con la postura tradicional de la doctrina en Chile, siendo mayoritaria la que considera al hurto un tipo de delito de actividad. Para Hernández, la tipificación del hurto no contiene descripción de resultado alguno:

\footnotetext{
${ }^{97}$ SEARLE, John, La construcción, cit. nota $\mathrm{n}^{\circ}$ 90, p. 62.

98 Véase, supra, p. 17 Lo anterior en ningún caso implica que sea fácil determinar dicho punto en el tiempo. Esto dependerá de distintos indicios que permitirán mostrar cuándo ya se puede hablar de total ruptura de custodia con constitución de una nueva custodia correlativa.
} 
OLAVE, Alejandra "El delito de hurto como tipo de delito de resultado".

“(...) la ley no exige ningún resultado que deba verificarse a consecuencia de la conducta típica de apropiación, comoquiera que se definan los alcances de dicha conducta". ${ }^{99}$

El problema está en que Hernández comienza de la premisa de que el resultado debe ser una consecuencia de la apropiación, pasando por alto que el resultado en el hurto es la apropiación (y expropiación correlativa). ${ }^{100}$

Yáñez, por su parte, defiende que la tipificación del hurto describiría una actividad, la que define como un "fenómeno complejo dirigido a hacer propio un bien mueble ajeno". ${ }^{101}$ Lo que Yáñez no parece notar es que existe un claro resultado en su definición: si se logra la finalidad de (a lo que está dirigido) semejante "fenómeno complejo", se hace "propio 102 un mueble ajeno". La apropiación en el caso del hurto y en su definición, es un proceso que en caso de culminar exitosamente logará, como el mismo Yáñez reconoce, “(...) la pérdida de la cosa por el titular o la lesión del bien jurídico". ${ }^{103}$ Hernández también reconoce que la conducta descrita en el tipo del hurto tiene "efectos", como la pérdida de la cosa por parte de su titular. Ahora bien, no explica por qué la pérdida de la cosa por parte de su titular es un "efecto" y no el resultado intrínseco del proceso de sustracción con ánimo de apropiación, llevado a cabo existiendo la correspondiente oportunidad.

En lo que sigue, se deberá responder a la pregunta acerca de la justificación que motiva a la doctrina a insistir en clasificar tipos que describen resultados intrínsecos como tipos de actividad. Hernández habla de una imposibilidad descriptiva de que el hurto sea un tipo de resultado, ${ }^{104}$ mientras Oliver afirma que, "[c]onforme a la propia definición legal de delito frustrado, es conceptualmente imposible que un hurto alcance a dicha forma de ejecución imperfecta." 105

En el primer caso ya se ha mostrado que el tipo del hurto describe la realización de una acción que acaba con un resultado intrínsecamente unido a ésta. Es la afirmación de Oliver la que ahora atañe, por lo que se revisará si es que efectivamente hay una "imposibilidad conceptual" de hurto frustrado.

\subsection{La tentativa acabada en delitos de resultado intrínseco}

La identificación de qué cuenta como la realización de todo lo necesario para que el crimen o simple delito se consume, sin que esto se verifique por causas independientes a la voluntad del autor, tratándose de un delito de resultado intrínseco, resulta especialmente difícil, tal como lo mostró la cita a Searle, ya que el resultado no se conecta causalmente con la acción realizada.

\footnotetext{
99 HERNÁNDEZ, “La nueva regulación”, cit. nota n 59, p. 6.

${ }^{100}$ Las consecuencias de la apropiación pueden identificarse como la etapa de agotamiento del delito. Entre ellas, paradigmáticamente puede reconocerse la posibilidad de disponer de la cosa.

101 YÁÑEZ, "Una revisión crítica", cit. nota n 10, p. 7.

102 Se utilizan las palabras de Yáñez para ilustrar el punto, pero no debe entenderse por “propio" una apropiación jurídicamente reconocida por la regulación civil. Como se explicó arriba (supra, p. 2), se trata de una relación fáctica entre un sujeto y un objeto, en que el sujeto toma como propio un objeto ajeno.

${ }^{103}$ YÁÑEZ, "Una revisión crítica", cit. nota $\mathrm{n}^{\circ} 10, \mathrm{p} .11$.

${ }^{104}$ HERNÁNDEZ, “La nueva regulación”, cit. nota n 59, p. 6.

105 OLIVER, Delitos contra la Propiedad, cit. nota ${ }^{\circ}$ 7, p. 125.
} 
Polit. crim. Vol. 13, № 25 (Julio 2018) Art. 5, pp. 175-207.

[http://www.politicacriminal.cl/Vol_13/n_25/Vol13N25A5.pdf]

A diferencia de las acciones causalmente complejas, en las que es conceptualmente posible identificar un momento en el que la acción completa ya se ha realizado, sin que el resultado haya acaecido, las acciones constitutivamente complejas se caracterizan por una conexión intrínseca entre acción y resultado: existiendo oportunidad para la acción, si se ejecuta la acción que ejemplifica el tipo de acción prohibida, necesariamente se da el resultado. Bajo esta estructura, la única forma en la que la ejecución de la acción no dé lugar al resultado es que no se dé la oportunidad. Tal como en los ejemplos del ciudadano no investido de autoridad que intenta votar como concejal y el inexperto jugador de ajedrez que trata de hacerle un jaque mate a un alfil, el autor que trata de hurtar algo propio, creyendo que se trata de algo ajeno, no podrá consumar un delito de hurto. Asimismo, una persona que intenta sustraer y generar un nuevo enclave de custodia de un objeto, por ejemplo, metiéndolo en su bolsillo, no podrá consumar el delito si es que su acción de meter el objeto en el bolsillo no pudo generar quiebre alguno en la custodia anterior por haber estado siendo observado por guardias en un supermercado. En estos casos, la inexistencia de una oportunidad para la acción no obsta a la ejecución completa de la acción, la que, de haber existido la oportunidad, hubiera efectivamente tenido como resultado un quiebre de custodia ajena y constitución de una nueva custodia sobre la cosa.

El espacio que entonces queda para la tentativa sólo puede identificarse con una representación errónea de que existe oportunidad para la acción, error que lleva a que la realización de dicha acción esté destinada a fallar. Un error sobre los presupuestos de hecho necesarios para producir el resultado típico, denominado comúnmente en la doctrina como "error de tipo al revés", bajo el principio de inversión ${ }^{106}$ se corresponde, según la doctrina tradicional, con la categoría de "tentativa inidónea".

Tradicionalmente en Chile, por "tentativa inidónea" se ha entendido aquella que se identifica como no apta para la realización del tipo, es decir, que no representa peligro alguno para el bien jurídico protegido. ${ }^{107}$ Bajo dicha categoría caerían aquellas acciones destinadas a fallar

\footnotetext{
${ }^{106}$ El principio de inversión ha sido criticado por Puppe, que lo caracteriza como una mala comprensión de la contraposición lógica. Del hecho de que el dolo sea una condición necesaria (pero no suficiente) de punibilidad, sólo se sigue que a falta de éste la conducta no será punible, puesto que su inversión nada dice acerca de otras condiciones necesarias para la punibilidad. Así, "[d]e esta conclusión invertida jamás deriva la determinación positiva definitiva de la punibilidad." Para explicar la apariencia de "inversión" que se da en la teoría del error, utiliza lo que llama el "postulado de la simetría": "un presupuesto de la punibilidad se considera o solamente objetivo o solamente subjetivo." Una suposición errónea sobre un hecho típico llevará a la tentativa inidónea cuando objetivamente no exista y a la exclusión del dolo cuando objetivamente exista. A su vez y de forma simétrica, una suposición errónea respecto de la ley penal llevará al delito putativo cuando objetivamente no exista o a un error de prohibición cuando objetivamente exista. Las críticas de Puppe resultan especialmente atingentes a la hora de determinar los alcances del dolo, en particular respecto de las llamadas "leyes penales en blanco", mas, para los efectos del presente trabajo, su postulado de la simetría es suficiente para comprender el paralelo planteado entre error de tipo y tentativa inidónea, y entre error de prohibición y delito putativo, respectivamente PUPPE, Ingeborg, "El error de hecho, error de derecho, error de subsunción", en: VV.AA. El error en el Derecho Penal, Buenos Aires: AD-HOC, 2010.

${ }^{107}$ Entendida desde una tesis objetiva de fundamento de la punibilidad de la tentativa, tesis a la que adhiere la mayor parte de la doctrina en Chile, basándose en la mención que hace el Código Penal en su artículo séptimo, inciso tercero, a "hechos directos", que se ha interpretado como una alusión a acciones que pongan efectivamente en peligro al bien jurídico, requisito propio de las teorías objetivas para fundamentar la punibilidad de la tentativa. Así, GARRIDO, Derecho Penal, Parte General, cit. nota n 2, pp. 274 y ss.; POLITOFF / MATUS / RAMÍREZ, Lecciones, cit. nota ${ }^{\circ}$ 5, nota 19 y p. 379; ETCHEBERRY, Derecho Penal, Parte General, cit. nota n ${ }^{\circ}$ 65, p. 62; BUSTOS, Juan y HORMAZÁBAL, Enrique, Lecciones de Derecho
} 
OLAVE, Alejandra "El delito de hurto como tipo de delito de resultado".

a causa de una errónea representación de que se presenta una oportunidad para la acción. Caen, por lo tanto, bajo esta categoría todos aquellos casos de tipos de resultado intrínseco en los que, a pesar de la completa realización de la acción, el resultado no se verifica. ${ }^{108}$ Esto quiere decir que la tentativa acabada de hurto es conceptualmente posible, siendo siempre reconocible como una tentativa inidónea.

\subsection{Hurto frustrado}

Como se ha visto, el delito del hurto es tipo de delito que puede presentarse en grado de frustrado, en la forma de una tentativa inidónea. Contrario a lo que se ha defendido tradicionalmente, bajo la propuesta acá defendida, por ende, no hay error alguno de parte del legislador al tipificar una variante de hurto frustrado. De hecho, existe amplia jurisprudencia en la que se revisan casos en los que el autor pone de su parte todo lo necesario para apropiarse de un bien mediante sustracción y ello no se verifique por causas independientes a su voluntad. ${ }^{109}$

El caso más común de aplicación del artículo 494 bis es el hurto en lugares comerciales que posicionan sus productos al alcance del público, permitiendo que sean los mismos consumidores los que lleven los productos a las cajas, para pagar su precio. Este es el caso de supermercados y grandes casas comerciales. Para compensar esa falta de seguridad, la mayoría de estos lugares cuentan con alarmas, guardias y cámaras de seguridad, que permiten asegurar que la custodia sobre los productos permanezca en manos de la empresa respectiva. En este contexto, los casos de relevancia para la pregunta por la frustración se dan cuando una persona es detectada sin ella notarlo por las medidas de seguridad, sustrayendo con ánimo de apropiación algún producto.

La importancia de estos casos es que las primeras dos de las tres posibilidades de respuesta, tentativa, frustración y consumación, han sido barajadas en la jurisprudencia. ${ }^{110}$ Algunas sentencias consideran que el hurto estaría en grado de tentativa, por no haber podido el autor abandonar el recinto (criterio requerido para la consumación), ${ }^{111}$ mientras que otras afirman que el hurto se encontraría frustrado, ya que "[a]1 hechor ya no le quedaba nada por hacer y si no consiguió su objetivo, lo fue por una causa independiente de su voluntad, esto es, la intervención del guardia que lo retuvo." 112

Penal, Vol. II, Madrid: Trotta, 1999, p. 268; NOVOA, Curso de derecho penal chileno, Tomo II, cit. nota $\mathrm{n}^{\circ} 2$, pp. 123-4 y pp. 127 y ss.

108 Así, JAKOBS, Günther, Derecho Penal, Parte General, Fundamentos y teoría de la imputación, $2^{a}$ ed. TRAD. CUELlO, Joaquín y SERRANO J. Luis, Madrid: Marcial Pons, 2009, p. 889 y MAÑALICH, Autotutela del acreedor y protección penal del deudor, Santiago: Eds. Jurídicas de Santiago, 2009, p. 161.

${ }^{109}$ Un acabado análisis de la jurisprudencia hasta el año 2005 se puede encontrar en FERNÁNDEZ, Álvaro, "Hurto-falta", cit. nota n ${ }^{\circ}$; FERNÁNDEZ, José Ángel, "Sentencias sobre determinación del iter criminis en la falta de hurto cometido en supermercados" Revista de Derecho de la Pontificia Universidad Austral 6, (2004), pp.229-240; RAMÍREZ, "La frustración", cit. nota n 82.

${ }^{110}$ En la sentencia Rol 402-2013, de la Corte de Apelaciones de Puerto Montt, la parte querellante presenta un recurso de nulidad contra la sentencia de Juzgado de Garantía que absolvió al imputado por considerar que se trataba de un hurto falta tentado, defendiendo que el delito se encontraba en grado de consumado. No se ha encontrado jurisprudencia que defienda dicha posición.

${ }^{111}$ Corte de Apelaciones de Chillán, sentencia Rol 267-2010 y Corte de Apelaciones de Valparaíso, sentencia Rol 803-2014

${ }^{112}$ Corte de Apelaciones de Concepción, sentencia Rol 55-2013, considerando $6^{\circ}$. 
Polít. crim. Vol. 13, № 25 (Julio 2018) Art. 5, pp. 175-207.

[http://www.politicacriminal.cl/Vol_13/n_25/Vol13N25A5.pdf]

Como ya se adelantaba, la consumación se puede descartar inmediatamente, ya que el resultado de la ruptura de custodia y la constitución de una nueva custodia sobre la cosa no se da; los mecanismos de vigilancia han impedido esta ruptura. En estos casos la custodia del titular, aunque debilitada, no se ha quebrantado por completo.

Ahora bien, corresponde hacer en este punto una aclaración. Este reconocimiento de que la custodia del titular, en casos en que se esconde la mercadería pero no se sortean todos los mecanismos de custodia, no se ha quebrantado por completo, se circunscribe al caso chileno. Como se ha visto, el concepto de custodia es uno cuya determinación es relativa a ciertos indicios prácticos. Así, como lo reconoce Sánchez-Ostiz, ${ }^{113}$ la doctrina y jurisprudencia alemana llegan a una conclusión diferente en el caso de una persona que sustrae y esconde la cosa en un "espacio reservado" (Tabusphäre, literalmente: esfera tabú), como un bolsillo de su pantalón o bolso. En este caso se reconoce un quiebre total de la custodia y, por lo tanto, la consumación. Esto muestra el carácter relativo que tiene el reconocimiento de los enclaves de custodia, dependientes de consideraciones socio-culturales. En Alemania, la estricta reserva que se tiene respecto a la privacidad y el espacio personal, en particular el propio cuerpo, justifican que, a pesar de que la persona esté siendo vigilada, la custodia se considere quebrantada cuando el objeto se esconde en un "espacio reservado". En Chile, en contraste, no bastaría con el solo ocultar los objetos dentro de este "espacio reservado", sino que se requeriría franquear todas las barreras, incluida la vigilancia de los guardias.

Distinto es el caso en el que los guardias no se dan cuenta de la sustracción, y esta culmina con el objeto guardado bajo un nuevo enclave de custodia. Ya que esta nueva custodia no es detectada por los elementos de seguridad, el objeto es sacado del control esperado del titular, quebrantándose su custodia y consumándose el hurto. Esto es reconocido por Carnevali quien, a pesar de seguir la teoría de la disponibilidad para fijar el momento de la consumación en el hurto, reconoce que en el caso en que una persona se encuentra en un supermercado e introduce mercadería dentro de su bolsillo, puede afirmarse que "(...) en el plano fáctico la cosa ha pasado a poder del agente."114

Este criterio no es seguido por la jurisprudencia de la Corte Suprema, la que, haciendo suya la teoría de la disponibilidad planteada por Garrido, ${ }^{115}$ ha fijado el límite entre tentativa y consumación en la línea de las cajas del establecimiento. Así, afirma la Corte Suprema:

"[L]a infracción se produce al traspasar las cajas registradoras sin cancelar [sic] el valor de la especie, en consecuencia, hasta antes de ese momento sólo había una mera tenencia de la especie y no una posesión como señor y dueño". ${ }^{116}$

Su argumento es que sólo al traspasar esa línea el autor está en posición (aunque sea por un instante) de disponer de la cosa como señor y dueño. Más allá de las críticas ya realizadas a

\footnotetext{
${ }^{113}$ SÁNCHEZ-OSTIZ, Pablo, "Consideraciones sobre los delitos de hurto y robo cometidos en establecimientos de autoservicio", Revista de Derecho de la Universidad de Piura, n 2, (2001), notas 20 y 21

${ }^{114}$ CARNEVALI, Raúl. "Criterios para la punición de la tentativa en el delito de hurto a establecimientos de autoservicio. Consideraciones político-criminales relativas a la pequeña delincuencia patrimonial”, Política Criminal, $\mathrm{n}^{\mathrm{o}} 1,(2006)$, p. 15.

${ }^{115}$ Véase, supra pp. 9-10.

${ }^{116}$ Corte Suprema, sentencia Rol 5125-2005. En el mismo sentido, Corte Suprema, sentencia Rol 889-2006. Así también, las sentencias de la Corte de Apelaciones de Concepción, Rol 55-2013 y Rol 131-2013, y de la Corte de Apelaciones de Santiago, Rol 2404-2014.
} 
OLAVE, Alejandra "El delito de hurto como tipo de delito de resultado".

la teoría de la disponibilidad, la Corte Suprema, al fijar un criterio estático relacionado con un punto específico en el espacio para el momento de la consumación, falla en comprender que el concepto de custodia es uno eminentemente práctico, que varía según las circunstancias. Así, basta con imaginar el caso en que empleados mismos del supermercado escondan bienes de éste, por ejemplo en el entretecho, para sacarlos al momento en que el supermercado se encuentre cerrado, y sólo ellos tengan acceso. Sería absurdo defender que el hurto no se encuentra consumado porque tales bienes no han superado la línea de las cajas.

\section{Conclusión}

El objetivo principal del presente trabajo ha sido proponer una interpretación del artículo 494 bis del Código Penal que le otorgue sentido, en contra de quienes defienden que sería imposible que un hurto se dé en calidad de frustrado, negando así que el legislador haya establecido reglas de imposible aplicación. Del análisis del tipo del hurto se concluyó que este describe una acción y no una actividad, luego de un análisis de la distinción, de cómo ha sido comúnmente entendida y de cómo debiera entenderse. En tanto acción, el hurto se clasifica como un tipo que describe una acción de resultado intrínseco, en la que el vínculo entre acción y resultado no es causal. Esta particularidad del hurto (y de otros tipos penales) implica que los únicos casos en que se estará ante un hurto en grado de frustrado son casos de la llamada "tentativa inidónea", en que se puede reconocer una imposibilidad de alcanzar el resultado ya al inicio de la ejecución, por no existir una oportunidad para la acción que se pretende ejecutar. Esta conclusión lleva a negar que un hurto frustrado sería conceptualmente imposible. De ahí que su tipificación tampoco debiese interpretarse como un error legislativo. En efecto, como ya se ha revisado, el hurto frustrado no solo es posible sino que pueden encontrarse abundantes ejemplos de hurto frustrado en la jurisprudencia.

Ahora bien, tanto en el ámbito nacional como en el derecho comparado existe vasta literatura y amplia discusión acerca de la identificación de qué cuenta como tentativa inidónea y si es que, una vez identificada, debería ser punible. Si bien, la pregunta acerca de la punibilidad de la tentativa inidónea es una que excede el ámbito del presente trabajo, no deja de llamar la atención que el legislador haya optado por tipificar como falta una hipótesis de tentativa inidónea, la que, en la medida en que el artículo 494 bis del Código Penal se mantenga vigente, será punible. 
Polít. crim. Vol. 13, № 25 (Julio 2018) Art. 5, pp. 175-207.

[http://www.politicacriminal.cl/Vol_13/n_25/Vol13N25A5.pdf]

\section{Bibliografía}

BASCUÑÁN, Antonio, "Delitos contra intereses instrumentales", Revista de Derecho de la Universidad Adolfo Ibáñez I, (2004), pp. 291-362.

BUSTOS, Juan y HORMAZÁBAL, Enrique, Lecciones de Derecho Penal, Vol. II, Madrid: Trotta, 1999.

CARNEVALI, Raúl. "Criterios para la punición de la tentativa en el delito de hurto a establecimientos de autoservicio. Consideraciones político-criminales relativas a la pequeña delincuencia patrimonial”, Política Criminal, nº 1, (2006), pp. 1-17.

COX, Juan Pablo, Delitos de Posesión, Montevideo y Buenos Aires: BdF, 2012.

CURY, Enrique, "Contribución a la distinción entre delitos de resultado y de simple actividad" Revista de Ciencias Penales XL, vol. 1, (1993), pp. 69-75.

CURY, Enrique, Derecho Penal parte general, $7^{a}$ ed., Santiago: Ediciones Universidad Católica de Chile, 2005.

DAVIDSON, Donald, Essays on actions and events, Oxford: Oxford University Press, 2002.

ETCHEBERRY, Alfredo, Derecho Penal, Parte General, Tomo II, $3^{a}$ ed. Santiago: Editorial Jurídica, 1997.

ETCHEBERRY, Alfredo, Derecho Penal, Parte Especial, Tomo III, $3^{a}$ ed. Santiago: Editorial Jurídica, 1997.

FEINBERG, Joel, Doing and deserving, Princeton: Princeton University Press, 1970.

FERNÁNDEZ, Álvaro, "Hurto-falta: Una reforma mal hecha y otra pendiente", Sentencias destacadas, Anuario de jurisprudencia: una mirada desde la perspectiva de las políticas públicas, Libertad y Desarrollo, (2005), pp. 89-104.

FERNÁNDEZ, José Ángel, "Sentencias sobre determinación del iter criminis en la falta de hurto cometido en supermercados" Revista de Derecho de la Pontificia Universidad Austral 6, (2004), pp. 229-240

GARRIDO, Mario, Derecho Penal, Parte General, Tomo II, $3^{a}$ ed. Santiago: Editorial Jurídica, 2003.

GARRIDO, Mario, Derecho Penal, Parte Especial, Tomo IV, $4^{a}$ ed. Santiago: Editorial Jurídica, 2008.

GOLDMAN, Alvin, A theory of human action. New Jersey: Prentice-Hall, 1970.

HART, H.L.A., El Concepto de Derecho, Buenos Aires: Abeledo Perrot, 2007, 336p. 
OLAVE, Alejandra "El delito de hurto como tipo de delito de resultado".

HERNÁNDEZ, Héctor, "La administración desleal en el derecho penal chileno", Revisa de Derecho de la Pontificia Universidad Católica de Valparaíso XXVI, (2005), pp. 201258.

JAKOBS, Günther, Derecho Penal, Parte General, Fundamentos y teoría de la imputación, $2^{a} e d$. TRAD. CUELLO, Joaquín y SERRANO J. Luis, Madrid: Marcial Pons, 2009.

KAHLO, Michael, "Determinación conceptual del derecho e interpretación sincrética en las relaciones de pertenencia propias del tipo de hurto", en: VV.AA. La insostenible situación del Derecho Penal, Granada: Comares, 2000 pp. 129-148.

KENNY, Anthony, Action, Emotion and Will, London: Routledge, (2003).

KERN, Eduard, Los delitos de expresión, Buenos Aires: Depalma, 1967.

KINDHÄUSER, Urs, “Hechos brutos y elementos normativos del tipo", InDret 2, (2014), pp. 1-24.

KINDHÄUSER, Urs, “Acerca de la distinción entre error de hecho y error de derecho", en: VV.AA. El error en el Derecho Penal, Buenos Aires: AD-HOC, 2010, pp. 139-163.

KINDHÄUSER, Urs, “El tipo subjetivo en la construcción del delito”, InDret 4 (2008), pp. $1-35$.

KINDHÄUSER, Urs, Estudios de Derecho Penal Patrimonial, Lima: Grijley, 2002.

LOMBARD, Lawrence, "Actions, results, and the time of a killing", Philosophia Vol. $8 \mathrm{n}^{\circ}$ 2-3, (1978), pp. 341-354.

MAÑALICH, Juan Pablo, "La violación como delito de propia mano", Revista de Ciencias Penales XLIII, $n^{\circ}$ 4, (2016), pp. 21-70.

MAÑALICH, Juan Pablo, Norma, causalidad y acción, Madrid: Marcia Pons, 2014.

MAÑALICH, Juan Pablo, "El delito como injusto culpable", Revista de Derecho Vol. XXIV, $\mathrm{n}^{\circ} 1,(2011)$, pp. 87-115.

MAÑALICH, Juan Pablo, Autotutela del acreedor y protección penal del deudor, Santiago: Ediciones Jurídicas, 2009.

MAÑALICH, Juan Pablo, “El 'hurto-robo' frente a la autotutela y la legítima defensa de la posesión”, Revista de Estudios de la Justicia 7, (2006), pp. 65-93.

MAÑALICH, Juan Pablo, “¿La comisión de delitos mediante la imputación de delitos?, Revista peruana de doctrina y jurisprudencia penales 6, (2005), pp. 193-242. 
Polit. crim. Vol. 13, № 25 (Julio 2018) Art. 5, pp. 175-207.

[http://www.politicacriminal.cl/Vol_13/n_25/Vol13N25A5.pdf]

MAÑALICH, Juan Pablo, "La tentativa y el desistimiento en el derecho penal. Algunas consideraciones conceptuales", Revista de Estudios de la Justicia n 4, (2004), pp. $137-175$.

MATUS, Jean Pierre y RAMÍREZ, Cecilia, Manual de derecho penal chileno: parte especial, Valencia: Tirant Lo Blanch, 2017.

MAYER, Laura, "El ánimo de lucro en los delitos contra intereses patrimoniales", Revista de Derecho de la Pontificia Universidad Católica de Valparaíso XLII, (2014), pp. 285-319.

MERA, Jorge, Hurto y robo, Santiago: Jurídica ConoSur, 1995.

MOURELATOS, Alexander, "Events, processes, and states", Linguistics and Philosophy $\mathrm{n}^{\circ}$ 2, (1978), pp. 415-434.

NOVOA, Eduardo, Curso de derecho penal chileno, Tomo I, 3 a ed. Santiago: Editorial Jurídica, 2005.

NOVOA, Eduardo, Curso de derecho penal chileno, Tomo II, 3 a ed. Santiago, Editorial Jurídica, 2005.

OLIVER, Guillermo, Delitos contra la Propiedad, Santiago: Thompson Reuters, 2013.

OLIVER, Guillermo, "Estructura típica común de los delitos de hurto y robo", Revista de derecho de la Pontificia Universidad Católica de Valparaíso XXXVI, (2011), pp. 359395.

POLITOFF, Sergio, Los actos preparatorios del delito: tentativa y frustración, Santiago: Editorial Jurídica de Chile, 1999.

POLITOFF, Sergio; MATUS, Jean Pierre y RAMÍREZ, Cecilia, Lecciones de Derecho Penal chileno, Parte General, $2^{a}$ ed. Santiago: Editorial Jurídica, 2004.

PUPPE, Ingeborg, "El error de hecho, error de derecho, error de subsunción", en: VV.AA., El error en el Derecho Penal, Buenos Aires: AD-HOC, 2010, pp. 132-189.

RAMÍREZ, Cecilia, "La frustración en delitos de mera actividad a la luz de determinadas sentencias", Revista de Derecho de la Pontificia Universidad Católica de Valparaíso XXVI, (2005), pp. 133-141.

ROXIN, Claus, Derecho Penal, Parte General, Tomo I, $2^{a}$ ed. Madrid: Civitas, 1997.

SÁNCHEZ-OSTIZ, Pablo, "Consideraciones sobre los delitos de hurto y robo cometidos en establecimientos de autoservicio", Revista de Derecho de la Universidad de Piura, $\mathrm{n}^{\circ} 2$, (2001), pp. 241-251. 
OLAVE, Alejandra "El delito de hurto como tipo de delito de resultado".

SEARLE, John, Making the social World, Oxford: Oxford University Press, 2010.

SEARLE, John, La construcción de la realidad social, Barcelona: Paidós, 1997.

SOTO, Miguel, La apropiación indebida, Santiago: Conosur, 1994, 100p.

VENDLER, Xeno, Linguistics in Philosophy 3 a ed., Ithaca: Cornell University Press, 1974.

VERA, Juan Sebastián, La consumación en el hurto, Santiago: Librotecnia, 2011.

VERA, Juan Sebastián, "La frustración en los delitos de mera actividad", Revista de Estudios Ius Novum 1, (2008), pp. 241-256.

VON WRIGHT, Georg Henrik, Norma y Acción, Madrid: Tecnos, 1970.

YÁÑEZ, Rodrigo, "Una revisión crítica de los habituales conceptos sobre el íter criminis en los delitos de robo y hurto”, Política Criminal Vol. 4, n 7, (2009), pp. 87-124.

ZUGALDÍA, José Miguel, "Delitos contra la propiedad y el patrimonio”, Revista Chilena de Derecho, Vol.15, n², 1988, pp. 395-397. 